\title{
SATISFACTION WITH RETIREMENT: \\ VOCATIONAL SCRIPT DEVELOPMENT
}

\author{
DISSERTATION \\ Presented in Partial Fulfillment of the \\ Requirements for the Degree Doctor of Philosophy \\ in the Graduate School of The Ohio State University \\ By \\ Joan Simon, B.A., M.A., Ph.D. \\ $* * * * *$
}

The Ohio State University

1996

Dissertation Committee:

Approved by

Samuel H. Osipow

Lyle D. Schmidt

W. Bruce Walsh

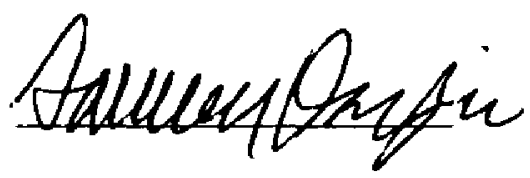

Adviser

Department of Psychology 
UMI Number: 9639347

$$
?
$$

UMI Microform 9639347

Copyright 1996, by UMI Company. All rights reserved.

This microform edition is protected against unauthorized copying under Title 17, United States Code.

\section{UMI \\ 300 North Zeeb Road \\ Ann Arbor, MI $\mathbf{4 8 1 0 3}$}


Copyright by Joan Simon 1996 
To Hugh and Ben 


\section{ACKNOWLEDGMENTS}

I thank my Adviser, Dr. Samuel Osipow, for his understanding, patience, unwavering encouragement, and insight. 
January $31,1947 \ldots \ldots$.

1968

1975-1980

$1980-1983 \ldots \ldots \ldots \ldots$

1981

1982

1983

1983-present

1994-1995
Bonl - Gloversville, New York

B. A., English Literature, English

Department, State University of New York at Buffalo, Buffalo, New York

Research Associate, The National Center for Research in Vocational Education, Columbus, Ohio

Senior Research Specialist, Decision Research Corporation, Columbus and Cleveland, Ohio

M.A., Educational Research and Evaluation, College of Education, The Ohio State University

Graduate Administrative Associate, Department of Sociology, The Ohio State University

Ph.D., Sociology, Department of Sociology, The Ohio State University

President, CJI Research Corporation, Columbus, Washington D.C., and Tucson

Psychology Assistant, Crittenton Family Services, Inc., Columbus, Ohio

iv 


\section{PUBLICATIONS}

"The New Legislation: Locating the Roots of Curriculum Concern," (1977) (with N. Singer), Joumal of Career Education, 4, (1), 15-21.

Adult Learning: Implications for Research and Policy in the Eighties (with N. Selz) (1979). Columbus: The National Center for Research in Vocational Education.

Work Experience and Academic Credit: Issues and Concerns (with R. Watts and S. Downing) (1979). Columbus: The National Center for Research in Vocational Education.

Functional Competencies for Adapting to the World of Work (with N. Selz \& W. L. Ashley) (1980). Columbus: The National Center for Research in Vocational Education.

The Effect of Format on Student Evaluations of Teaching (unpublished masters thesis) (1981), Columbus: The Ohio State University.

Residential Satisfaction Among Displaced Urban Residents (unpublished doctoral dissertation) (1983), Columbus: The Ohio State University.

"Satisfaction with Retirement: Vocational Script Development," (Spring 1995), Applied and Preventive Psychology: Current Scientific Perspectives, 4, (2), 101-111.

"The Continuity of Career," (with S. H. Osipow), (in press), The Career Development Quarterly. 


\section{FIELDS OF STUDY}

Major Field: Psychology

Studies in:

Vocational/Career Psychology

S. O. Osipow

Psychology of Aging

L. D. Schmidt

Ethics and Professional Issues

Vocational Assessment

W. B. Walsh

Counseling/Psychotherapy

N. Betz

R. Russell

Cognitive Psychology

P. Highlen

Developmental Psychology

D. Dell

Comparative Psychology

J. Gibbs

Social Psychology

S. Boysen

Industrial/Organizational Psychology

T. Brock

History and Systems

R. Billings

Statistics and Psychometrics

D. Hothersall

F. Damarin

T. Browne

R. Nygren

R. McCallum 
TABLE OF CONTENTS

ACKNOWLEDGEMENTS $\ldots \ldots \ldots \ldots \ldots \ldots \ldots$ iii

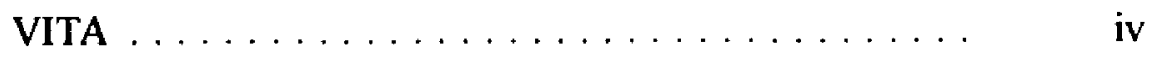

LIST OF TABLES $\ldots \ldots \ldots \ldots \ldots \ldots \ldots \ldots$ viii

LIST OF FIGURES $\ldots \ldots \ldots \ldots \ldots \ldots \ldots \ldots$ ix

CHAPTER PAGE

I. INTRODUCTION $\ldots \ldots \ldots \ldots \ldots \ldots \ldots \ldots$ I

II. METHOD $\ldots \ldots \ldots \ldots \ldots \ldots \ldots \ldots \ldots, \quad 38$

III. RESULTS $\ldots \ldots \ldots \ldots \ldots \ldots \ldots \ldots \ldots$.

IV. DISCUSSION AND SUMMARY $\ldots \ldots \ldots \ldots .89$

APPENDICES

A. Human Subjects Forms . . . . . . . . 98

B. Demographic/Lifestyle Questionnaire ... 101

C. CASRO Code of Standards for Survey

113

D. Permissions $\ldots \ldots \ldots \ldots \ldots \ldots \ldots \ldots$

LIST OF REFERENCES $\ldots \ldots \ldots \ldots \ldots \ldots \ldots \ldots \quad 119$ 


\section{LIST OF TABLES}

TABLE

PAGE

1. Retirees: Sample Demographics $(\mathrm{N}=79) \ldots \ldots .52$

2. Retirement Aspects: Mean Satisfaction Ratings

(In Order of Decreasing Satisfaction) ....... 58

3. Retirement Satisfaction (RS) Index . . . . . . . 59

4. Salience Inventory Scores for Retirees ...... 61

5. Correlation Matrix for all Variables ....... 66

6. Anti-Image Correlation Matrix ......... 71

7. Initial Statistics, Factor Structure Matrix,
and Final Statistics $\ldots \ldots \ldots \ldots \ldots \ldots \ldots \ldots \ldots$

8. Rotated Factor Matrix $\ldots \ldots \ldots \ldots \ldots \ldots \ldots .81$

9. Regression Analysis of the Predictors of

Retirement Satisfaction . . . . . . . . . . . . 86

viii 


\section{LIST OF FIGURES}

$\begin{array}{lll}\text { FIGURE } & \text { PAGE }\end{array}$

1. Regression Equation: Predictors of

Retirement Satisfaction .............

85

ix 


\section{CHAPTER I}

\section{INTRODUCTION}

Over the past few years, the mature segment of the large baby-boomer cohort has begun to envision retiring. A few have already done so. The push by employers for early retirement, business and industry buyout incentives, diminished returns on investments, and the prospect of fixed incomes and rising expenses are well known features of work and retirement today. These features demand that the boomer cohort turn to planful husbandry of social, psychological, and emotional resources such that retirement can be enhanced and satisfying. Other socioeconomic and cultural evolutions are equally salient for this group. Greater numbers of women in the work force and entering the work force at older ages may suggest that some women will retire later than men, forcing renegotiation of male/female roles and responsibilities in the household. Increased productivity in business and industry appears to be following severe retrenchment and may have created a retirement-age group that sees retirement comprising part-time and serial occupational and entrepreneurial endeavors. Leisure, education, and employment may become 
more widely dispersed across life stages, precluding stereotypical pigeon-holing of education among the young, employment among those from $20-65$, and leisure among only older people. The boomers' parents, living longer, and the boomers' children, bon to later-in-life parents, help define the boomers as the "sandwich generation." As such, they may serve both as caregivers to aging parents and as providers of health, education, and welfare for a new generation.

Given these influences, the scenarios of retirement today take on a far different tone than they have in the past. They present siguificantly different sociological, economic, and psychological issues for pre-retirees, retired people, and the professionals who will assist them in this part of the life cycle. The dimensions of vocational satisfaction may well become those of life satisfaction for people entering retirement: status, achievement, social relationships, and time (Hitchcock, 1984). The very basic questions Havighurst, Munnichs, Neugarten, and Thomae (1969) asked years earlier have value today: ". . how [do] people structure their lives ... when they retire from or lose some of the roles of middle age? What is the nature of their experience, how do they pattern their interpersonal relations and under what conditions do they achieve life satisfaction" (p. 3)? 
Assuming that individuals carry with them through life cycle changes some habituation to or affinity for role, interpersonal style, status, values, and interests, we can infer that the extent to which one carries forward (in time) a fulfilling view of one's employed self is the extent to which one can enter a retirement that could be satisfying in most realms. Friedan (1993), in her new account of the aging experience, describes the "retirement paradox" as, in part, movement toward development of interests, avocations, and talents in the face of a socio-cultural mystique that disables the "strengths of maturity" (p. 201). Hitchcock (1984) describes the counselor's role as assisting the retiree in repackaging previous vocational strengths so they are efficient and beneficial features of the types of work retirement can offer. Others suggest that planning, the extent to which occupational goals were met, and health and economic status moderate the extent to which postretirement activity is consistent with preretirement activity (Beehr, 1986) and that counseling psychologists should focus on work in people's lives as opposed to the values inherent in a focus on career (Riclardson, 1993).

Retirement counseling can become more effective by admitting the existence of an enduring "vocational script." However, this critical concept has not been articulated as a psychological, social, and emotional reality that has implications for the planning and design and enjoyment of one's retirement. 
The purpose here is to delineate the features of the vocational script, to describe the role of a nurtured vocational script in satisfaction with retirement, and to illuminate similar and contrasting constructs among several major psychological theories of personality and development. Reference to these constructs can identify points of convergence with the concept of vocational script and assist in the development of integrated counseling and treatment strategies.

Parenthetically, it appears that no one has advanced a theory of retirement to date that is more specific than a theory of aging. Neither is it the purpose to do this here, for the development of a theory of retirement will require unraveling a multitude of internal and situational variables. However, review of the features and theoretical bases for the vocational script concept can be one part of the effort.

\section{The Vocational Script Concept}

Satisfaction with retirement involves both environmental factors (social, political, and economic) and personal factors (psychological aspects, attitudes, abilities, styles, and capacities), though our focus in this paper is the psychological elements. A "vocational script" is a person's unique characterization of vocational identity independent of specific jobs, positions, and careers. It is a screenplay that is not set in time. It adapts as 
environmental factors change over time and interact with the person's skills, capacities, habits, and developing personal styles. It is more than personal identity, because it defines how one functions when one works. It defines how the self views and has adapted to the extrinsic aspects of work as well as in what ways and to what extent the self values intrinsic features of work. A vocational script is a person's way of thinking about the self as it has navigated the functions and features of work. In this sense, the vocational script operates both vocationally, as one defines oneself in jobs, positions, or careers, and avocationally, as one defines one's behavior, values, attitudes, and expectations in hobbies, leisure activities, or volunteer work. A person may define him/herself as deferential to authority, as someone who "gets the job done," pays attention to detail, and who has a highly developed feeling for working as part of a team. Another might call him/herself the one who has the "ideas" others put in place, who has need for a high degree of personal autonomy, who has a clear sense of direction, and who functions as a leader for others. These vocational "descriptions" of self, and many other such characterizations, are presented by clients or elicited by counselors all the time in personal career counseling. However, rarely are they considered pivotal in the construction of the self in retirement. Retirement planning and counseling typically have as their primary focus assisting people in effecting financial security and 
responding to concens about housing, social support networks, health care, and aging. Too often, even when these needs are addressed satisfactorily, and even when retirees engage in leisure and volunteer or part-time work activity, retired people continue to feel bereft of role, status, and usefulness.

Becoming aware of one's vocational script is healthy, healing, and enfranchising. Empowering people to use their scripts in retirement planning and adaptation can strengthen individuals' expectations of self-efficacy and satisfaction with life in retirement from active employment. It is important to note here some of the most primary influences on retirement satisfaction if we are to further clarify vocational script development. First, the perceived social and cultural "rights" and "duties" of the retired person influence the extent to which the retired person copes, adapts, and becomes satisfied with the retirement role (Atchley, 1991). "Rights" are economic support absent a job, personal autonomy in allocation of personal resources and time management, and those rights that derive from prior occupational association (membership in and access to employer-sponsored services), all this minus "the stigma of being regarded as dependent on society" (Atchley, 1991, p. 209). "Duties" are those expectations of the retired person that include avoidance of full-time employment, the Social Security benefit deduction on excess earnings, and the expectation that there will be a "carry over into retirement ... [of] skills, 
experience, knowledge, and identity with the jobs or positions" held previously, all this without "becoming economically dependent on either . . . families or the community" (Atchley, 1991, p. 209).

The retirement role as a relationship also influences coping, adaptation, and satisfaction (Atchley, 1991). Whereas the employed person's role is viewed as having "instrumentality," the retired person's role in our culture is "similar to the position of alumnus or alumna", and the description of the retired role includes "terms that are flexible and qualitative rather than concrete and instrumental" (Atchley, 1991, p. 209). Atchley (1991) points out parenthetically that "jobs also have important qualitative aspects, but these are seldom emphasized in 'job descriptions' or in discussion about jobs, which is perhaps a major oversight" (p. 209).

The extent to which the work ethic carries over into retirement affects the extent to which retired persons feel satisfied and productive. This "busy ethic" (Ekerdt, 1986) helps people in retirement give meaning to their leisure activities and peripheral status vis-a-vis the employed world. It gives them solidity and protects them from criticism of non-performance. As Atchley (1991) points out though, it is "the continuation of the abstract ethic of work into retirement," not a "new instrumental role," that provides meaning (p. 209). And so people in retirement engage in activities with a goal directedness that 
exudes seriousness of purpose and intended productivity, even when those activities are leisure ones directed toward self-maintenance and resource management (Atchley, 1991). This assumes, then, that people in retirement can be encouraged to perceive their "non-world-of-work" activities as part of a continued work ethic, a carry over of the productivity they experienced in their occupations and careers. Enforced by social institutions (one's social support network, the media), Ekerdt's (1986) "busy ethic" carries the work ethic into retirement. It is not too remote an assumption that the view of oneself in the vocational role (including both occupational affinities and avocational interests) might well enhance satisfaction with the retirement role.

Counselors can help individuals to define this view by assisting them in telling their vocational stories and defining the essential, adaptive, and dramatic features of the self at work. These features will include how the self has responded to (and defended against) work activities and routines, how it has adapted to varying levels of status, role complexity, and compensation, and how it has functioned interpersonally in work relationships. Such counseling for vocational script development assists people in the character development so essential in successful fiction and drama. The analogy is apt. Fully developed characters are as critical in the satisfying resolution we seek in 
literature and drama as they are in the satisfaction we seek in work and avocations. Both imply the resolution of self.

\section{Related Theoretical Constructs}

Narrative psychology theory and the concept of life review let us tease out relationships to vocational script development (Sarbin, 1986; Sherman, 1991; Schafer, 1992; Tarman, 1988; Carlsen, 1988 \& 1991). Sarbin's concept of the "self-deceiver" focuses on people's skill in either "spelling out engagements in the world" or not doing so, a process that would require the "observer" [sic] to do several things: investigate the person's self-narrative; determine whether the person is the narrator or the protagonist; and be able to interpret incongruence in the narrative (Sarbin, 1986, p. 16-18). Vocational script development implies similar investigation. As a person develops his/her vocational script, s/he reveals characters, plot, engagement, role, and status. In comparable ways, narrative, Sherman (1991) explained, gives form and meaning to reminiscence and draws on something far different from Freud's determinism. Moving from the perspective of Butler's (1963) life review concept, Sherman (1991) conducted three studies in the mid to late ' 80 's to investigate the effects of reminiscence among older people on socialization, self-efficacy, coping functions, and narrative function. He found that the life narrative reveals intentionality and character, clues, as it were, to causes and 
purposes in individuals' lives. Schafer (1992) and Tarman (1988) hold similar views. Maintaining that "there is value in viewing the self in narrative terms," Schafer (1992) explained his concept of multiple selves (the actual self, ideal self, self as place, self as agent or subject, and self as object, et al.) and cautioned against losing sight of the "proliferation of selves" in people's narratives. Using the "interpretive approach," Tarman (1988) examined studies on reminiscence and life review in order to illuminate the relationship between autobiographical presentation of self and adjustment of older persons. He offered several propositions that explain consciousness as internalized social context and called for an understanding of life review studies in terms of their "social ingredients," not their developmental stage evidence (Tarman, 1988, p. 177). Echoing Goffman (1959) and Berger and Luckmann (1979), Tarman concludes that biographical construction among older adults is a way of negotiating a beneficial social reality. This is precisely what vocational script development provides -- a negotiated justification of goals and experiences. Another recent formulation (Mair, 1989) clarifies how the vocational script concept varies from typical psychological interpretation. Mair (1989) offered a Kellian perspective and suggested several ways in which story-telling ("creative fictions") "allow[s] expressions of psychological life that mere facts can never achieve" (p. 11). Mair suggested the value of seeing that language 
production, not only private experience, can be key in this regard, that the telling of the story (not the analytical procedures) is primary, and that the manner of telling is as great a clue to psychological understanding as the content of the tale. He maintained that our "psychological reporting" is impoverished because it attends only to "verbal matters" and ignores the centrality of stories in the shaping of individual personality. Also ignored is the "politics of telling," "the hidden structure of power and privilege in which the speaker [client] and audience [counselor] are located" (p. 9).

One more approach relates constructive development to counseling for career transition, a key link for development of the vocational script concept. McAuliffe (1993) describes the individual's interpretive framework as central to a dynamic view of career development (McAuliffe, 1993). Any individual operates within one of three balances: the interpersonal balance, the institutional balance, or the interindividual balance. The interpersonal balance relies on external sources of identity and interpretation, typical of those who do not question widely held beliefs about certain vocational paths or occupations. Career is not a calling for those who act from within an interpersonal balance. Individuals within the institutional balance act assertively and independently in their vocations and careers but may not, precisely because of their lack of reflection, be able to make an "authentic career quest" (McAuliffe, 1993, p. 24) 
or to identify core values and preferences outside of the organizational role.

The third balance, the interindividual balance, is a more flexible framework in which the adult constructs meaning in a negotiating process, taking in new experience and transforming the self.

One key influence is reminiscence itself -- the extent to which individuals are willing to engage in reminiscence and how frequently they do so. Such willingness and frequency have been linked to greater life satisfaction, positive self-esteem, and more effective adaptive behavior and coping skills (Havighurst \& Glasser, 1972; Lewis, 1971; McMahon \& Rhudick, 1964). And, noting Butler again, reminiscence is seen as precipitating the life review, a positive, integrating process (Butler, 1963). Similarly, Antonovsky \& Sagy (1990), using the Erikson model heuristically, see reevaluation of one's world view and reevaluation of life satisfaction (as analyzed in the lives of Israeli retirees) as major transition challenges between generativity and integrity.

The process of developing one's vocational script demands negotiation of the self's relationship to past events, attitudes, and behaviors so that the self becomes more unique. The process is similar to Tobin's (1985) explanation of how individuals maintain the continuity of personality through a referential process of justifying and altering events. However, the concept of vocational 
script involves a "truer" referential process, a more authentic development of a core story of the self. The vocational script concept also includes elements of 'Tomkins' script theory (Tomkins, 1979,1987; Carlson, 1981) but differs in key ways. Carlson (1981) described Tomkins' script theory $(1979,1987)$ as an alternative to linear models of investigation. The theory presents a dynamic personality model in which the individual constructs his/her world from its earliest history by producing, casting, directing, acting, and criticizing. In Carlson's study of the development of a "nuclear script" by a 30-year old adult he pointed out the failure of traditional theories to deal with three issues: "the activity of the individual in selecting and transmuting early experience; the particularity of the individual case; and the diversity of personality structures" (Carlson, 1981, p. 503). Tomkins' theory is understood in light of assumptions about personality structure, dynamics, and development. Personality structure in script theory includes "scenes," which have object and affect as well as place, time, and action. There are also "scripts," that are comprised of a person's predictions, interpretations, and responses and the rules governing these activities, such that, over time, scripts gain the power to determine scenes. Personality dynamics in script theory involves "psychological magnification" or the building of affect. In this process, scenes become interconnected through the "recruitment of memories, thoughts, actions, and 


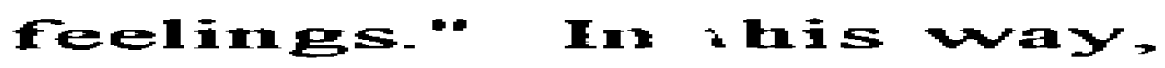
disappoinitudents"or for $(C a-150 m, \quad 981,10-503)$

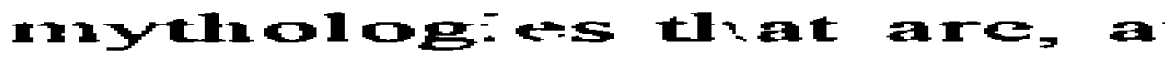
deweloprimint, Linem, is t chamacteristics, and mud create. THLethetry

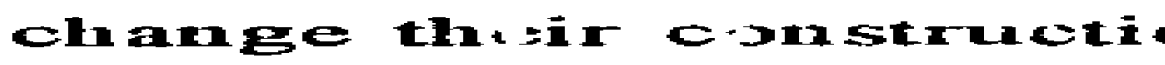

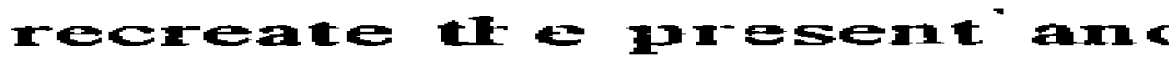
The = $-0=$ aticomal

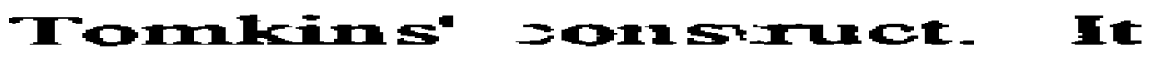
Tomakims $c=50 x i b e s y+110$ Wocatiomal seript dewel im rellation to whomk, mot

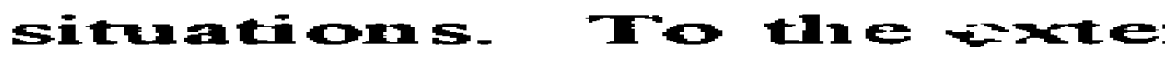
is simainat =0 Tromakitus" a Wiew of lliestifit is

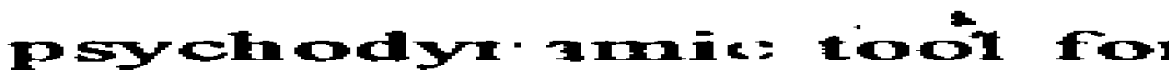

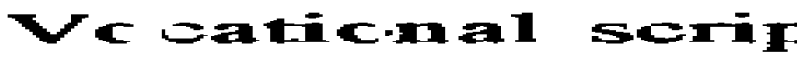
issues bunt diwerges from 
feelings." In this way, new experience is "scanned for old dangers and disappointments" or for "detection of differences around a stable core" (Carlson, 1981, p. 503). A person might also develop ideal scenes, mythologies that are, at the same time, coping mechanisms. Personality development, then, is the development of scenes, which present salient life characteristics, and the development of scripts, which offer ways to respond and create. The theory is based in a two-way temporality. Individuals can change their construction of past events through later experiences but can also recreate the present and revise the past vis-a-vis their views of the future.

The vocational script development concept has many of the elements of Tomkins' construct. It has the dynamic, dramatic construction of scene that Tomkins describes, the scanning of new experience, the building of affect. Vocational script development, though, iloves toward a description of the self in relation to work, not just to a file drawer of scripts to be used in new situations. To the extent that vocational script development enlists memory it is similar to Tomkins' theory. To the extent that the vocational script becomes a view of the self it is less a dynamic personality model and more a psychodynamic tool for maintaining the self in everyday life.

Vocational script development involves a resolution of developmental issues but diverges from the ideas of developmental stage models. The concept 
is not necessarily linear, cumulative, or predictive. Erikson (1963, 1968;

Erikson \& Erikson, 1986) would agree. While Freud's psychosexual stage theory, Jung's stages of psychotherapy (confession, elucidation, education, and transformation), and Adler's individual psycloology and theory of the life line all offer basic support for the concept of vocational script development, it is Erikson (1963, 1968; Erikson \& Erikson, 1986) who stands out among the "grandfathers" in this regard, for his emphasis on adaptation and on adult life stages. Erikson considered successful resolution of conflicts between adaptive and maladaptive behavior essential in psychosocial development. His stages are present throughout life. Adaptive and maladaptive attitudes, ego strengths, and orientations to life are the bases for developmental issues that become prominent or defused across all stages at some time in the life cycle. But it is when Erikson (1986) talks about retirement and old age that we see an Eriksonian view of a scripted life, the carrying forward of a recollected, reconstructed, and re-evaluated personal past. He explains that "many of the developmental concerns of earlier and earliest stages are being refaced, as the then-acquired capacities, traits, and involvements are now undergoing some disdevelopment" (p. 53). If we see Erikson's concept of "refacement" as a change in perspective-taking, it is only a short conceptual jump to a view of refacement as re-scripting. The acquisition of refacement competencies in 
retirement requires then, as Erikson (1986) says, internal motivation, selfdiscipline, and intrinsic reward and perceived adequacy -- a carrying forward of the vocational script. For Erikson, the process is interpretive. This is a feature of the vocational script development concept also. It is interpretive in that it enables the individual to explain his or her role and context.

Others have described this interpretive process as a creative activity (Levinson, 1986; Datan, Rodeheaver, \& Hughes, 1987). They have implied that a constructive feature of that activity, a narrative, results. Levinson's (1986) merging of the developmental and socialization perspective bears some similarity to vocational script development. One element of his theory, "individual life structure," differs fundamentally from personality theory in its emphasis on the individual's relationship to the external world (p. 6). Levinson's research confirms his theory in part. In his study of men's lives he found that "structure-building" periods alternated with "structure-changing" periods (Levinson, 1986). As his subjects transitioned into structure-changing periods of time, choice-making, meaning-making, and commitment were the keynotes. Like vocational script development, the process was creative and constructive, a re-creation of self.

Some theorists (Datan, Rodeheaver, \& Hughes, 1987) have suggested that the study of life span development be "liberalized," such that we begin to 
understand that we are really studying life stories, attempts "by the individual to create a narrative given order and predictability only by the choices and decision-making of that individual" (Datan et al., 1987). As Datan et al. explained, it is the individual's "sense of continuity" (p. 163) and the individual's attempts to maintain that continuity that constitute adult personality.

They also described new methodologies in the study of the life span ("intrapsychic interdisciplinarity"), suggesting an increased interest in the individual as being constructive of the environment, and in cognition in relation to other processes and the social and cultural environment. Some of these new methodologies, adopted by gerontologists, include various biographical techniques that result in construction of a narrative. It is this narrative that can intimately involve the researcher [counselor] and provide a social and cultural context for interpretation. The process results in what Freeman (1984) calls "historical understanding," understanding the psychological present and future of the individual in terms of "the shape that emerges out of the past" (p. 17). We hear echoes of the "mechanics" of vocational script development in other adult personality theories. Vocational script development implies that there is "evaluation" of one's history in the development of one's vocational script, that this evaluation is intuitive, and that there are numerous resolutions 
to life problems once the vocational script is illuminated. Similarly, Cohler \& Grunebaum (1981) suggested that the criteria should include comprehensiveness and consistency as well as the capacity for absorbing other types of data. Lerner \& Busch-Rossnagel (1981) suggested that interpretation should focus on how individuals produce their own development, not on quantitative measures. Labouvie-Vief (1984), in critiquing Piagetian exclusion of later adult types of reasoning, offered a view of adult thinking and problem-solving in which older adults come increasingly to rely "on intuitive and personal" thinking and reasoning, that they consider multiple resolutions to problems, and that the Piagetian bias precludes seeing this failure of formal operational thinking as anything but cognitive decline.

Recent cognitive perspectives enhance the concept of vocational script precisely because they accord to proactive adaptation to individuals. Vocational script development suggests that environmental influences on development are joined with physical, cognitive, and emotional growth processes and that both stability and change are key features. We see a similar perspective in new constructivist approaches. People proceed through cycles of organization and disorganization, emotional attachments are key, and thought, feeling, and action are intertwined (Mahoney \& Lyddon, 1988). Cognitive structures are not vehicles for storing a stable response set but are, rather, transformational. 
In vocational script development, the individual moves through a process that invites personal growth and adaptive response. Similarly, for constructivists, reality becomes personalized through a generative process. There is a view of development across the lifespan and an interest in basic change processes, both of which are related to recent interest in evolutionary epistemology (Mahoney \& Lyddon, 1988). The development of self-identity (Guidano, 1984, 1987, 1991), is a self-organizing process that allows for both mutability and stability. Increasingly complex cognitive abilities develop, enable the individual to reinterpret and re-order experience, and make possible the recreation of a self-identity. The vocational script concept provides a description of the self that is generative, regulated, and assertive. The construct of "autopoiesis" (Varela, 1979; Zeleny, 1981) also provides a description of self-identity similar to that inherent in the vocational script concept but with a primary focus on "autonomy" (Varela, 1979).

Vocational script development implies an adaptive repertoire of behaviors and attitudes grouped and ready to respond to events. So do the constructs of Bowlby (1969) and Bandura (1991). Bowlby (1969) developed his ethological theory of an "adaptive behavioral repertoire," following both Darwinian adaptation theory and Harlow's work with monkeys as well as Lorenz' imprinting theory. Specifying a sequential link between an instinct for 
survival and eventual independence of the organism, Bowlby unfolded a theoretical description of the attachment developed in the infant as key to eliciting responsive caregiving. As the infant, by instinct, develops behaviors that elicit caring, loving response in the caregiver, the infant ensures his/her survival and subsequent cognitive development. The development of cognition further ensures survival and enables the child to function more independently from the caregiver.

Bandura (1991) suggested that the "ongoing exercise of self-influence" motivates and regulates behavior (p. 248). He explained that "a number of factors, some relating to the attributes of individuals, others to the behavior, and still others to the nature and type of self-monitoring, can affect the likelihood that observing how one behaves will enlist self-reactive influences" (p. 251). For Bandura, self-monitoring is influenced by "preexisting cognitive structures" and by "mood states." People exercise "adaptive control anticipatorily rather than being simply reactive to the effects of their efforts" ( $p$. 259).

Bandura then explained how three kinds of influences within the self regulate motivation: affective self-evaluation, perceived self-efficacy, and adjustment of personal standards following attainment -- i.e., an evaluative and adaptive process built upon individual differences and values, precisely what 
the vocational script development process involves. Bandura continued with explanations of belief systems that are influential in self-regulation. He described such belief systems as "conceptions of ability," and people's beliefs in the controllability of their environments, and then summarized these concepts in a causal model. Pervading these concepts, Bandura's causal model, and his subsequent discussion of "depression-prone individuals" is the concept of the endurance and dynamics of personality traits (pp. 272-274), again, the stasis and change that pervade the vocational script concept.

Also central to the vocational script concept is the idea of core themes that reflect past response and can be predictive of future attitudes and behavior. Guidano's (1991) concept of "core affective themes" and Liotti's (1988) "matching and making process" exemplify this idea. Core affective themes develop throughout the lifespan. For the individual these themes constitute the base for interpreting experience and adding new understandings to the core themes. Thus, change and continuity are always present as the individual gives meaning to experience (Guidano, 1991). The "matching and making process" describes a similar system. As the individual perceives new elements in his or her experience, they are matched to information previously stored. If the new elements force repeated incongruence between what has previously been represented and how these new elements are interpreted, new patterns of 
memory develop and transform subsequent representations of experience (Liotti, 1988).

Vocational script development links the psychology and philosophy of work and career with social and cultural contexts, for it offers a tool for mining the resources to be found in an individual's history of work. Similar but slightly varying constructs (Lofquist and Dawis, 1969; Campbell and Heffernan, 1983; Tiedeman and $O^{\prime} H a r a, ~ 1963$; Tiedeman and Miller-Tiedeman, 1977; Schein, 1978; Musgrove, 1992; \& Savickas, 1992) relate to this mining process in their explanations of the continually created self. Schein's (1978) "career anchors" concept is rooted in the individual's organization of his or her own experience, just as is vocational script development. A career anchor guides, facilitates, modulates, identifies, and evaluates one's experience. Internally defined, career anchors are of several types: technical/functional competence; managerial competence (analytic, interpersonal, and emotional); security; autonomy; and creativity (Schein, 1978). Tiedeman and MillerTiedeman's view of the self "that is continually under construction" ( $1977, \mathrm{p}$. 167) is a key link to the narrative paradigm and the vocational script concept. Tiedeman and O'Hara's (1963) very early statements about time, work, and ego identity underlie the view of vocational development as a construction of the self over time. Both activity and reflection are important components of 
experience, demanding that a person "fit his career into life" (1963, p. 57).

This focus on the "continuing self," on the ability of the person to recreate the self in the context of various life roles is at the heart of vocational script development. The self "calls forth" its history, recapitulates it in the creation of a satisfying present, and anticipates a "vital" future: the essence of a satisfying retirement from active employment.

The history, memory, maintenance, and repair of one's vocational script can be active in the development of satisfaction with retirement, both in the approach to and planning for retirement and in the actual experience of retirement. Musgrove (1992) and Savickas (1992) extend a constructivist perspective and provide a significant backdrop to the development of the vocational script concept. Musgrove (1992) described her career counseling with a client unfolding in three stages. In the first stage, her work is that of a counseling psychologist with an integrative approach. Here she uses psychoanalytic, Gestalt, object/relations, Adlerian, and cognitive therapies to uncover "deep, broad issues," to "pull out the stories leading to vocational resolution," and to define the "residuals . . from earlier relationships." In the second stage, she "work(s) from the conviction that the client is carrying a complete job description within him/herself and that if we both learn how to raise the client's level of self-observation thoroughly enough, we can 'read' it." 
In this second stage, she is "interested in every clue to the person's vocational identity ... the nuances of the person's work life." In the third stage, she becomes a "coach," assisting in job search skill development and activities. For Musgrove, the internal job description is key to personal identity, for the implication is that such an internal "description" is in fact a far wider ranging view of the self as the individual constructs the self over time. Musgrove's approach to career counseling as psychological work is a response to a view of the self as being called forth, breaking through its wall of defenses, and acting from a core script.

The metaphor of character development, described earlier, infuses the vocational script concept and underlies a much larger metaphor, that of the narrated life. As a person develops his/her vocational script and brings it into awareness, s/he engages in a narrative process, telling a story of a life defined in large measure by the work s/he did. Referring to new developments in psychology and counseling that focus on narratives, or "career as story," Savickas (1992) concluded that this focus allows us to "conceptualize career counseling as a process of enhancing the narratability of a client's life" (p. 10). This done, he envisions that clients will see the future with less hesitation and "step into the next chapter" with the conviction that their stories are being continued. This is one purpose of vocational script development as well. 
Savickas argued that the "autobiographical project" is what the client "does" and that (recalling script theory) this project in fact produces the client's life. This "story metaphor" is in marked contrast, Savickas said, from viewing the client from the "trait metaphor," for the trait metaphor locks the client in time and the assumption that "the life produces the autobiography" (Savickas, 1992, p. 2). The story metaphor in fact enhances decision-making. It enables the client to make meaning of choices, altematives, and decisions because it "privileges the subjective perspective" of the client. Savickas uses narratability to do three things: reveal the thematic pattem of the client's life in which the person strives, through the stories, to "become more whole;" clarify the client's identity through the "formative and definitive experiences" in the client's stories; and extend "their stories into the occupational future" (1992, p. 5-6).

Further clarification of the vocational script concept can be found in the career development literature if we use occupational satisfaction as a conceptual surrogate for retirement response. A definition of occupational satisfaction derives from the definition of "work." Super (1976) defined work as "the systematic pursuit of an objective valued by oneself (even if only for survival) and desired by others; directed and consecutive, it requires the expenditure of effort. It may be compensated (paid work) or uncompensated (volunteer work or an avocation). The objective may be intrinsic enjoyment of the work itself, 
the structure given to life by the work role, the economic support which work makes possible, or the type of leisure which it facilitates" (Super, 1976, p. 20). Here, work is not precisely equivalent to occupation. All occupations are work, but not all work is an occupation. But the basic psychological emphasis in Super's definition is that elements of occupation, and therefore occupational satisfaction, relate to the definition of work. Occupational satisfaction can occur when the beliefs and values related to the job, as well as the job tasks and the motivation to complete the tasks, are congruent with the individual's dispositions and needs at a particular point in time. This perspective on occupational satisfaction does not preclude the effect of social context, but rather imbeds individual response in both the environment and individual differences.

Career development research and theory address directly issues surrounding occupational satisfaction and its psychological motivations and, by inference, subsequent response and adaptation to retirement that can be developed through vocational scripts. Both Osipow (1983) and Herr and Cramer (1988) offer helpful categorizations in this regard. And recently, Super (1984) has commented anew on work and job satisfaction: "The approach of recent years has shifted from a focus on work alone as the central life concern to an interest in the quality of life, life in which work is one central concern in 
a constellation of roles such as homemaking, citizenship, and leisure that interact to make for life satisfaction. The terms work motivation and job satisfaction are now perhaps not displaced by, certainly incorporated into, the terms quality of life and life satisfactions" (Super, 1984, p. 29).

\section{Implications for Counseling}

If we view the development of retirement satisfaction as the continued development of the individual's vocational script, then the individual's awareness of the script, continued adjustment of the script, and perceived congruence of life activity with the script can be seen as key independent personality variables. These are of course influenced by socioeconomic and cultural factors: the availability of resources, ethnic/racial group membership, occupational status, educational attainment, social support, and labor market and economic conditions. And the entire array is affected by the extent to which counselors are effective in enhancing awareness, acceptance, and skill in developing the vocational script. When an individual can develop a view of his or her vocational self that is continuous from the time of active employment through retirement, self-efficacy, optimism, planfulness, autonomy, and satisfaction can accrue.

Counseling applications that address development of a personal vocational script enhance the congruence of the perceived vocational self in 
employment with the self in retirement. The applications that follow all encourage the development of a person's vocational script, the elaboration of that script, and the application of that script in the experience of retirement activities and goals.

Savickas (1989) assists clients in learning about "the social meaning of work and love in our culture" (p. 7) and in doing so provides one model for intervention. He hopes to help clients resolve "work-love imbalance" in which there is discrepancy for his retiring clients between how they have always seen themselves in the work world and how they see themselves in daily life outside of employment. Savickas works with his clients to re-orient their "interpretations of work and love that sustain disequilibrium and cause distress" (1989, p. 8). He does so by encouraging clients to interpret their definitions of their roles and activities vis-a-vis love and work and to balance the two worlds. In explaining the dichotomies faced by his clients, Savickas offers us some of the clothes that dress vocational scripts, those views of one's vocational role that carry over and penetrate one's retirement from a career. He says, "Competition must alternate with cooperation, aggression with altruism, efficiency with patience, control with reciprocity, and individuality with empathy" (Savickas, 1989, p. 11). 
Savickas (1990) made clearer the counseling application for people in retirement when he explained career interventions that "increase self-control and willpower. . . enhance self-efficacy, focus causal attributions on effort, and strengthen the need for achievement" (p. 3). Doing this helps people control their views of their own futures, because it helps them leam that they have had careers. Extending this idea, such career interventions help people in retirement bring their vocational selves with them as an aid in empowerment and satisfaction. Savickas (1990) called for counseling that helps people identify their "subjective careers." Whereas a person's objective career consists of positions the person has held, the subjective career "consists of selfconscious thoughts about the vocational past, present, and future," a time perspective and future orientation that encourages successful vocational behavior (Savickas, 1990, p. 4).

Savickas goes on to describe the middle-class career culturets time perspective orientation as something that can be learned by other cultures in the U. S. who have substantively different views of time and therefore face little success and satisfaction vocationally. He suggests that subjective career awareness can be taught through the use of three constructs in career intervention counseling: perspective, differentiation, and integration. These constructs address how people in what Savickas (1990) calls the "career 
culture" express time metaphors, maintaining that time metaphors that indicate direction and movement relate to career satisfaction. Assessing view of time begins by asking clients to complete the sentence, "Time is like " (Savickas, 1990, p. 6). It can also include assessment of temporal orientation, which Savickas explains as the "time zone [past, present, or future] . . [that has] primary relevance for contemporary decision making" (1990, p. 6). This can be done by using a "lines test" (Cottle \& Peck, 1969, as cited in Savickas, 1990). In this assessment, clients segment a horizontal line into past, present, and future areas, with the longest area considered their primary time orientation. Savickas (1990) also suggests using Cottle's (1976, as cited in Savickas, 1990) circles test.

Temporal differentiation, how "real" the primary time zone is for a person, is also assessed in counseling (Savickas, 1990). A highly differentiated time zone, populated with a wide range of relationships and experiences, grounds a person in that zone. Encouraging clients to differentiate the future time zone in such a rich fashion means, for Savickas, that those people can then actually see themselves in the future. This relieves anxiety and stress and allows for empowerment, autonomy, and purposefulness. "Anticipating events and then modeling the future using these events enables an individual to envision possible selves embedded in that future" (Savickas, 1990, p. 8), Aids 
in assessment of time orientation include Wallace's (1956, as cited in Savickas, 1990) Open Events Test, Tolor, Brannigan, and Murphy's (1970, as cited in Savickas, 1990) modification of Stein, Sarbin, and Kulik's Future Events Test (FET), anticipatory guidance (predicting the events in one's future to enhance adaptability), use of media excerpts and teaching resources to teach about future life and career stages, and use of future daydreams (guided imagery, future autobiographies). Such aids allow the counselor to use dreams as if they were scripts, encouraging clients to make the dreams "denser" and more extensive (Savickas, 1990).

Savickas' (1990) third organizing construct, time integration, helps the client become more planful, for it encourages the client to connect events across the past, present, and future. By doing so, the client achieves "continuity" (essentially, planning skill) and "optimism" (the disposition underlying planfulness) (p. 11). Savickas (1990) argues strongly for counseling that encourages such continuity and optimism, without which planning becomes an illusion, and unpredictability reigns. When clients can achieve a sense of continuity across time in relation to their view of their vocational selves, themes and patterns come to awareness and endure, identity is strengthened, and perseverance in activities becomes a hallmark of daily life. Savickas (1990) suggests assessment of continuity with Wessman's (1973, as cited in 
Savickas, 1990) Long-Term Personal Direction Scale and assessment of optimism with either Heimberg's (1961, as cited in Savickas, 1990)

Achievability of Future Goals Scale or Snyder, Harris, Anderson, Gibb, Yoshinobu, Langelle, Hamey, Halleran, and Irving's (1989, as cited in Savickas, 1990) Hope Scale.

Other practitioners, researchers, and theorists offer similar applications related to vocational script development. Currently conducting what she calls "structured life reviews," Haight $(1982 ; 1988 ; 1989 ; 1992)$ provides us with substantive practical examples of uses of this critical relative of vocational script exploration. Her Life Review and Experiencing Form (1982) encourages integration of life events, further examination, re-framing, and closure. The form consists of questions focusing on childhood, adolescence, family and home, and adulthood, and includes 17 summary items. Although items addressing vocational choice, decision-making, and development are few in number, the potential for developing such items is substantial and would be useful in eliciting vocational scripts in counseling sessions.

Schlossberg (1976) suggested several elements in adult counseling that apply to the use of vocational scripts: introducing adults to anticipation and implementation as two processes of decision-making; brainstorming; program development and social activism; and getting to the "subtext" (p. 35). 
Similarly, Super's career maturity assessment model (1983), with its emphasis on "crystallization" of experience and life-career roles across the life span could be useful in investigating and defining vocational scripts. Smyer's (1984) discussion of life assessment and "guided autobiography" supports these applications as do Westcott's (1983) work with life review with older persons (focusing on the themes of self-esteem, intergenerational conflict, preparation for living, and preparation for dying), Loesch's (1980) life-flow leisure counseling (exploring previous and current interests, values, and characteristics and subsequent integration into a desired set of leisure activities), and Johnson and Riker's (1981) work with the concept of "retirement maturity" (a construct locally normed with Super's Career Development Inventory).

Sherman (1991), dipping further into the area of reminiscence, self, and "narrative knowing," also provided support for the use of vocational script development to enhance retirement response. Sherman's (1991) discussion of Gendlin's Experiencing (EXP) Scale explained expressive and stylistic indicators of various experiential levels at any one moment during a person's self-narrating. These EXP levels range from the first level, when the narrative content is external events and the narrator is impersonal and detached, to the seventh level, when the content integrates external events, descriptions of feelings, propositions about feelings and personal experiences, and resolution of 
personal issues. Because they are process oriented, these levels label useful benchmarks for the counselor who seeks to enhance a client's ability to engage in useful narration.

\section{Summary and Problem Statement}

People entering retirement face an onslaught of situational, environmental, emotional, economic, and psychological changes for which they are largely ill prepared. At best, they may find assistance in community support groups or employee assistance programs that address such issues as budgeting and use of leisure time. At worst, they may lose a primary life role as an employed person and lack the skills to adapt to the changes in status and identity that result. While retirees may carry with them into retirement the social roles of spouse, partmer, parent, student, or volunteer, their vocational roles and identities often fade quickly, leaving many bereft of the benefits such an identity can provide. The meaning of work and the importance of the vocational role vary among people, but identifying these features of vocational identity can help people adapt to retirement. It may well be that those people who can participate in and commit fully to life in retirement have been able to realize values and expectations that accrued as part of their previous work identities. Such continuing vocational agency may in fact be the key ingredient in satisfaction with retirement. 
Personal career counseling can help in the cultivation of vocational agency. It can assist people about to enter retirement or in retirement in becoming aware of their perceptions of their vocational roles. It can do so through encouraged reflection on, reminiscence about, and definition of the various aspects of their work roles, how those roles became formed, and how those roles played out in the context of other life roles and their family and social relationships.

The key question, then, is how we might assess the extent to which people advance their vocational views of self into retirement. It is this assessment and the encouraged reflection from counseling that can result in the development of vocational scripts, those adaptive views of the self at work that provide the role definitions necessary for people to feel productive and responsible and, therefore, satisfied with retirement.

\section{Research Hypotheses}

The purposes of this study were to examine the effects of perceived importance of the work role, the extent of participation in various life roles, and the value expectations attributed to life role activities on retirement satisfaction. This is a new area of research in vocational psychology, linking vocational development theory, career counseling theory, and narrative and script theory to retirement satisfaction. As such, it requires that the research 
questions for this study be framed as working hypotheses. This study explored the following hypotheses:

1. Retired people who attribute greater importance to the work role and work-like roles (vs. other life roles) in their lives will be able to identify better the vocational features they have carried with them into retirement activity than those who attribute greater importance to other life roles.

2. Retired people who participate more fully in work-like activities (activities with purposes beyond relaxation and entertainment) in their retirements will report higher levels of satisfaction with their retirements than those who do not participate as fully in work-like activities.

3. Retired people who expect to become more involved in worklike activities in their retirements will report higher levels of satisfaction with their retirements than those who do not expect to become more involved in work-like activities.

4. Retired people who perceive they will have more opportunities to use their skills and knowledge in work-like activities will report higher levels of satisfaction with their retirements than 
those who do not perceive they will have more such opportunities. 


\section{CHAPTER II}

\section{METHOD}

Subjects

This study used professional telephone interviewers from a local social research company (CJI Research Corporation) to conduct survey interviews by telephone with a random selection of persons in Upper Arlington, a suburb of Columbus, Ohio. The telephone questionnaire used an introductory script to ask whether the respondent had retired within the past two to four years. If the respondent had retired in that time, he or she qualified for inclusion in the survey and was asked if he or she wished to participate. If so, the full questionnaire was administered over the phone. From a sample frame of 500 , 289 calls were made. From these calls, 57 were not answered, 66 declined to participate, and 87 were not qualified according to the research criteria. Extensive follow-up calls were also made to those whose lines were busy or who did not answer. A total of 79 interviews were completed.

Criteria for qualification and recruitment also required that the sample be sex balanced and include a range of pre-retirement occupational status to the 
extent possible. For this study, only residents of Upper Arlington were included in the sample. The sample was a convenience sample and, as such, allowed for recruitment at a much lower cost per interview than would wider sampling retirees within similar upper socioeconomic strata. Such generalizability is appropriate to an initial study testing working hypotheses such as those proposed herein.

After completing the phone survey, respondents were asked to participate in a follow-up mail survey. This procedure is described below.

\section{Measures}

The constructs referred to in the working hypotheses were operationalized through administration of The Salience Inventory (Super \& Nevill, 1985) accompanied by a demographic/lifestyle questionnaire. The Salience Inventory (SI) registers participation in, commitment to, and value expectations related to five life roles previously identified by Super (1976) in his Life-Career Rainbow: student, worker, homemaker (including parent, spouse, partner), leisurite, and citizen. The Rainbow helps illuminate the amount of time spent by a person in a particular role (temporal importance), the extent of emotional involvement in that role, and the variation of temporal importance and emotional involvement with personal and environmental determinants. 
Using the Rainbow as a base, the Work Importance Study (Super, 1982) developed a model of the importance of work and other life/career roles. The model has three components: commitment -- the emotional attachment to role that does not necessarily imply action; participation -- the extent to which a person expends time and energy in a role; and knowledge -- the cognitive aspect that a person acquires through actual experience in a role (not accounted for in the SI but, rather, in other inventories). A subsequent model was developed and expressed in the construction of the SI. The model underlying the SI is Super's (1983) Developmental Assessment Model that includes the psychological elements of the development of career within other life role contexts and brings the concept of "salience" into view. Salience combines the components of commitment and participation and the nature of values held by a person. With the inclusion of the salience concept, the model enables the counselor to determine career maturity and, by extension, readiness and preparation for other life roles (Super, 1984).

Super (1983) has suggested definitively that the SI can be useful in research on career maturity, and Nevill and Super (1986) suggest further uses in studying the importance of each role as roles change over time, the impact of the roles on one another, the values sought in each role, and role choices and satisfactions. The SI could be used to determine how salient needs and 
values would be addressed as a person moved from employment to retirement, as well as, in this study, to assess continuation of the vocational view of self and the relationship of retirement satisfaction to perceived salience of life roles.

The SI includes 170 items that can be self-administered and answered within 30 to 45 minutes. It has three parts that assess salience of life/career roles: studying, working, community service, home and family, and leisure activities. Three scales are scored on the SI: the Participation scale (P), the Commitment scale (C), and the Value Expectations scale (V). The response ratings range from "1" (Never or Rarely, and Little or None) through "2" (Sometimes and Some) and "3" (Often and Quite a Lot) to "4" (Almost Always and $A$ Great Deal). The SI is completed on answer sheets, which are electronically scored by the publisher. Scoring was done by the study investigator.

The $P$ scale is a set of 10 items that are behavioral in content. They ask "what you actually do or have done recently" with respect to four-point ratings across the five life roles. Participation is the measure of action, not emotional attachment to role or knowledge about a role. The $\mathrm{C}$ scale measures the extent of commitment to role ( 10 items; four-point scale) by asking "how you feel about" the five roles. It is the attitudinal, affective component of the SI and assesses degree of identification with each role. The $V$ scale asks "what 
opportunity do you see now or in the future to ..." and, as such, measures the extent to which a person expects to find satisfaction in a given role. The $\mathrm{V}$ scale assesses value expectations through 14 items on the four-point scale across 14 values that include both intrinsic and extrinsic values (Nevill \& Super, 1986). The 14 values and their corresponding item stems are:

1. Ability Utilization

2. Achievement

3. Aesthetics

4. Altruism

5. Autonomy

6. Creativity

7. Economics

8. Life Style

9. Physical Activity

10. Prestige

11. Risk

12. Social Interaction

13. Variety

14. Working Conditions use all your skills and knowledge in ... know that your efforts will show in ... make life more beautiful by . . . help people with problems in ... act on your own in ... discover or make new things in ... have a high standard of living through ... live life your own way in ... be physically active in ... be admired for your knowledge/skills in . . feel that you can take some risks in ... do things with other people in . . . do a number of different things in ... have good conditions for ...

Nevill and Super (1986) explain that these items were selected from the Values Scale (Super \& Nevill, 1986) for three reasons: independence and reliability as estimates of the items' representation of the universe of values; discriminating nature of the values with respect to occupations, as shown in other studies; and economy of administration. 
Measures of internal consistency (alpha coefficients) were above .80 for three test populations (high school and college students and adults). Test-retest measures of stability (college students) were less than .70 for 10 of the 15 scales (Super \& Nevill, 1986). Varying the sequence of the SI did not affect the reliabilities of the Values Expectations scale. These reliabilities remained lower than those for either the Participation or the Commitment scales.

Content validity of the SI derives from the career development literature base used to specify the life roles. Refinement of definitions of these roles was based on field trials. Item construction derived from reactions of subjects, staff agreement, and item-scale correlations.

Construct validity measures are evident in the relative rankings of the five life roles endorsed by the high school, college, and adult subjects. The rankings reflect developmental changes. Among the adult population, Leisure becomes less important. Commitment to Home and Family and Value Expectations in Home and Family become more prominent. However, the worker role ranks second among the five roles across all three scales for adults. Interscale correlations for the three populations (concurrent validity) show that Commitment is measured by both the Values Expectations scale and the Commitment scale. Theoretically, the two scales are similar. Theoretical difference is found in the Participation scale, which shows less correlation to 
the other two scales. Convergent and divergent validity of the scales are supported (Nevill \& Super, 1986).

The demographic/lifestyle questionnaire, developed by this author and administered prior to respondents' agreement to complete the SI, includes items to determine age, sex, race/ethnicity, prior occupational status, current retirement income range, social supports, financial responsibilities, retirement duration, retirement decision type (voluntary/involuntary), and the relationship of vocational/career features to activities in retirement. It also includes an index of items to measure level of satisfaction with retirement. Respondents were asked to indicate on a ten-point scale their well-being on the following features of their retirements:

disposable income

daily worry, vigilance, and stress extent of positive social contact quality of interpersonal relationships quality of involvement in community/neighborhood activities cohesion within the community in which they live attitudes of others with respect to their retirement status health concems independence/autonomy 
perceived ability to age in place

self-esteem

optimism

perceived personal agency

A measure of internal consistency (alpha coefficient) of this index was above .90 for the test population of retired adults. Test-retest measures of stability for the test population were above .60 for 7 of the 15 scaled items. Lower stability measures for the remaining $\mathbf{8}$ items may reflect small cell sizes $(N=16)$. The unbiased estimate of reliability under the strict parallel model is .89 .

\section{Design}

This study explored the hypotheses that retired people who attribute greater importance than do others to the work role and to work-like roles, participate in and commit more fully to work-like activities, and perceive that they will have more opportunities to use their skills and knowledge in worklike activities will be able to identify better the vocational features they have brought to their retirements and will report higher levels of satisfaction with retirement. More specifically, we expected to find that the greater the importance attributed to work-like activity and work-like roles in the SI, the higher a retired person would score on the Retirement Satisfaction Index (RS) 
in the demographic/lifestyle questionnaire. We also expected that the more retired people participated in activities related to working (paid or unpaid work or community service), the higher they would score on the RS. And, we expected that the more retired people felt commitment to, and had expectations of engaging in, work-like activities, the higher their RS scores would be.

Initial frequencies and breakdowns of the survey data (demographic/lifestyle questionnaire) and the SI results provided direction for subsequent analyses by specifying significant combinations of levels of variables. Factor analysis and multiple regression defined the relationship among the independent variables (the SI scales $C, P$, and $V$ and demographic/lifestyle characteristics) and their effects on retirement satisfaction (RS), the dependent variable. The regression model was: $\mathbf{R S}=\mathbf{C}+\mathbf{P}+\mathbf{V}+$ demographic/lifestyle variables.

Procedure

The Upper Arlington Commission on Aging and the Upper Arlington Senior Association assisted in this study of recently retired people. The study data will provide the Commission on Aging and Senior Association with information useful in program development. A full summary report on the study, including selected tables and narrative, will be provided to the Commission and Senior Association. 
As stated in the Subjects section of this chapter, CJI Research Corporation (CJ) conducted the survey interviews using its professionally trained staff of interviewers. The interviewers were trained according to professional interviewing practices. Participation by respondents was entirely voluntary, and strict rules guaranteeing confidentiality of responses and respondent identities were followed. These rules are those found in the Code of Standards for Survey Research of the Council of American Survey Research Organizations (CASRO) (see Appendix C). The survey interviews were conducted with a random selection of retired persons in Upper Arlington. The introductory script qualified the respondent as a person retired within the past two to four years and asked for his or her participation in the full phone interview. A total of 79 interviews were completed. The sample was sex balanced and included a range of pre-retirement occupational status to the extent possible.

The role of the Commission and the Senior Association in this supplemental study was limited to two components: providing access to recently retired respondents in the community interested in becoming involved in interviews as randomly selected respondents; and providing comments on the survey instruments to be used. 
The Commission and the Senior Association announced the upcoming survey in the community newspapers, validating the nature of the study and encouraging retired people to participate in the survey if they were called at random. The Commission and Senior Association were provided advance copies of the survey instruments to be used in the project for their review and approval. Appropriate revisions were made in the demographic/lifestyle questionnaire, and the instrument was pretested with five respondents selected at random. Revisions based on the pretest were included in the final instrument.

After the full phone interview, using the demographic/lifestyle questionnaire, was completed, the voluntary cooperation of the respondent was sought to complete a supplementary mailed questionnaire that would further explore retirement issues. This questionnaire was the SI. CJI staff prepared and completed the mailing to willing respondents, ensuring confidentiality according to CASRO standards, and using unique identifiers that would link SI respondents to their respective phone survey questionnaire data. A replacement sample, also uniquely identified, was used to control for attrition of subjects, and all cases of phone survey respondents who declined to participate in the mail survey were retained as a collateral sample for comparison of data results. All other identifying information referring to names, addresses, or telephone 
numbers was destroyed in paper and data files within three months after the end of the project and before delivery of the summary report. The unique identifiers were used only for data matching. Completed SI instruments, mailed back to CJI, were scored and merged with their respective phone survey components.

Proper approvals were obtained from The Ohio State University Human Subjects Committee. Participants were told in the letter mailed with the SI instrument that the investigator would remain available for a limited time for discussion of study results. 


\section{CHAPTER III}

\section{RESULTS}

Initial Demographic and Satisfaction Information Analysis of the information collected in the phone survey and in the mailed SI questionnaire $(\mathrm{N}=79)$ reveal a sample of retirees which is two-thirds (67\%) male, who were employed full-time (97.5\%) in largely professional (46.8\%) and managerial (20.3\%) positions prior to retiring, and who perceived they had "careers" ( $83.3 \%$ ), not just jobs/or positions, during their employed years (see Table 1). Other demographic characteristics are consistent with this profile, suggesting a relatively well-educated, affluent retiree sample. Almost $85 \%$ of the retirees are college educated. Over three-fourths $(75.9 \%)$ are married (most without other people in the household -- 77.2\%). And the majority (79.4\%) fall within the $65-74$ age range (a range that will begin to be filled over the next decade with the first wave of the baby boomer cohort). 
The general nature of the sample's retirement is also clear from the demographic data. The data appear to show a sample of retirees who have not been forced to retire and who do not suffer overmuch from economic pressures. Almost all the retirees (91.7\%) state they experienced a voluntary retirement decision. (Of these, 74\% say they "wanted to retire" and were not offered an early retirement offer.) Although $58.2 \%$ say their retirement activities are "very different from the work I did" while employed, a full $40.5 \%$ find that their retirement activities are either "like the work I did" or a "mixture" of employment-like activities and different routines. And while, as expected, there is a gap between pre- and post-retirement household income (see Q28 and Q29 in Table 1), it is not the large gap that might be evident in lower socioeconomic groups of retirees. 
Table 1

Retirees: Sample Demographics ( $N=79$ )

Variable

$\%$

Q1 Sex

Male

67.0

Female

33.0

Q3 Occupation During Employment

$\begin{array}{ll}\text { Professional } & 46.8\end{array}$

Managerial 20.3

Other (Sales, Service, Clerical, Trade) 32.9

Q4 Employment Type

Full-Time

97.5

Part-Time

2.5

Q4a Employment Type in Retirement

Part-Time

32.9

Volunteering

20.3

Mixture

2.5

Completely Retired

44.3 
Table 1 (continued)

Variable

$\%$

Q4b Part-Time Employed/Volunteering Retirees:

Similarity of Current Work to Pre-Retirement Work $(n=44)$

Very Similar

22.7

Somewhat Similar

27.3

Not Similar at All

34.1

Unsure

15.9

Q5 Type of Retirement Decision

Voluntary

91.7

Involuntary

5.6

No Response

2.8

Q6 Want to Retire? $(n=77)$

Wanted to Retire

74.0

Early Retirement Offer

Both

Q7b Perceived "Career" or "Jobs/Positions"?

Career

83.3

Both

16.7 
Table 1 (continued)

Variable

$\%$

Q8 Perceived Similarity of Retirement

Activities to Pre-Retirement Work

Are Like the Work I Did

26.6

Very Different from Work I Did

58.2

Mixture

13.9

Unsure

1.3

Q24 Education

High School

15.2

College

49.4

Graduate/Professional School

35.4

Q25 Marital Status

Married

75.9

Not Married

24.1

(Widowed

13.9)

(Divorced

6.3)

(Single

3.8) 
Table 1 (continued)

Variable

$\%$

Q26 Household Size

One

16.5

Two

77.2

Three

6.3

Q27 Age (n=68)

$55-64$

13.2

$65-74$

79.4

$75+$

7.4

Q28 Gross Retirement Household Income ( $n=64)$

Under $\$ 50,000$

54.7

Over $\$ 50,000$

45.3

Table 1 (continued)

Variable

$\%$ 
Table 1 (continued)

Variable

$$
\%
$$

Q29 Gross Pre-Retirement Household Income $(n=66)$

Under $\$ 50,000$

27.3

Over $\$ 50,000$

72.7

Note. Because of branching from Q5, n was too reduced to record responses to Q7a.

Levels of satisfaction in various aspects of retirement were also gauged in the phone survey. Retirees were asked to rate on a $1-10$ scale $(1=$ very dissatisfied; $10=$ very satisfied) their levels of satisfaction with the following elements of life in retirement:

extent of positive social contact

quality of interpersonal relationships quality of involvement in community/neighborhood activities cohesion within the community in which they live attitudes of others with respect to their retirement status health concerns independence/autonomy 
perceived ability to age in place

self-esteem

optimism

perceived personal agency

Table 2 shows the rank order of mean ratings (from highest to lowest) of these aspects. The retirees indicated their highest satisfaction with three aspects: (Q1 1/12 Quality of Interpersonal Relationships, 9.20; Q20 Perceived Ability to Age in Place, 9.09; and Q22 Optimism, 9.05). The next three highest rated aspects were Independence and Autonomy, Self-Esteem, and Attitudes of Others toward Retirement Status, followed closely by Extent of Positive Social Contact, overall Retirement Satisfaction, and Perceived Personal Agency. The aspects gamering the lowest satisfaction ratings were Quality of Involvement in Community, Health Concerns, and Community Cohesion. (See the questionnaire in Appendix B for the full item statements of each aspect.) 
Table 2

Retirement Aspects: Mean Satisfaction Ratings (In Order of Decreasing

Satisfaction)

Aspect Mean

(Q11/12) Quality of Interpersonal Relationships $\quad 9.20$

(Q20) Perceived Ability to Age in Place $\quad 9.09$

$\begin{array}{ll}\text { (Q22) Optimism } & 9.05\end{array}$

$\begin{array}{ll}\text { (Q18/19) Independence and Autonomy } & 8.96\end{array}$

$\begin{array}{ll}\text { (Q21) Self-Esteem } & \mathbf{8 . 8 4}\end{array}$

(Q15) Attitudes of Others Toward Retirement Status $\quad \mathbf{8 . 7 4}$

(Q10) Extent of Positive Social Contact 8.63

(Q9) General Retirement Satisfaction $\quad 8.58$

$\begin{array}{ll}\text { (Q23) Perceived Personal Agency } & 8.51\end{array}$

(Q13) Quality of Involvement in Community 6.99

(Q16/17) Health Concerns $\quad 6.98$

(Q14) Community Cohesion $\quad 6.94$ 
A "retirement satisfaction index" (RS) was constructed from the retirees' ratings of these aspects and from the one overall rating (Q9) of their general satisfaction in retirement. (See Table 3.) This index shows almost $32 \%$ of the retirees indicating high levels of retirement satisfaction across the rated aspects, with another $44.3 \%$ moderately satisfied. A little less than one-fourth (24.1\%) of the retirees indicated low levels of retirement satisfaction. This variable (RS) was used as the dependent variable in the subsequent regression analysis.

Table 3

Retirement Satisfaction (RS) Index

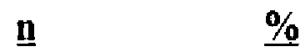

Low RS

19

Moderate RS 35

High Rs 25 31.6

Participation, Commitment, and Value Expectations Across Life Roles

As explained earlier, the SI was used in this study to assess continuation of the vocational view of self and the relationship of retirement satisfaction to perceived salience of life roles. The three parts of the SI assess salience of 
life/career roles: studying, working, community service, home and family, and leisure activities. Three scales are scored on the SI: the Participation scale (P), the Commitment scale (C), and the Value Expectations scale (V). The response ratings range from " 1 " (Never or Rarely, and Little or None) through "2" (Sometimes and Some) and "3" (Often and Quite a Lot) to "4" (Almost Always and A Great Deal).

Total scores, means, and standard deviations for the sample of retirees within the five life/career roles and across the three scales are shown in Table 4. The $P$ and $C$ scales have a maximum total score possible of $\mathbf{4 0}$ and a minimum of 10 . The $V$ scale has a maximum of 56 and minimum of 14 .

Across the three scales, home/family and leisure activities receive the highest scores. Retirees thus indicated that they engage in $(\mathrm{P})$ these roles more frequently than they do in studying, working, or community service and that they attribute greater importance (C) to these roles and expect to express various values (V) in these roles in the future.

The studying role received the lowest mean score across the three scales. Working and community service mean scores fell between the top ranked home/family and leisure roles and the low-ranked studying role (see Table 4). 
Table 4

Salience Inventory Scores for Retirees

$\begin{array}{lllll}\text { Variable } & \text { Mean } & \text { SD } & \text { Total Score } & \text { N }\end{array}$

Participation (What you actually do or have done recently) (Maximimum $=40)$

P-Study

18.85

7.46

1395.00

74

P-Work

19.65

6.54

1513.00

77

P-Service

20.20

6.33

1495.00

74

P-Home

28.45

5.32

2134.00

75

P-Leisure

28.04

6. 10

2103.00

75

Commitment (How you feel about it) $($ Maximum $=40)$

$\begin{array}{llccc}\text { C-Study } & 21.43 & 8.87 & 1629.00 & 76 \\ \text { C-Work } & 22.67 & 7.78 & 1723.00 & 76 \\ \text { C-Service } & 23.05 & 6.43 & 1729.00 & 75 \\ \text { C-Home } & 35.26 & 5.38 & 2715.00 & 77 \\ \text { C-Leisure } & 30.37 & 7.15 & 2308.00 & 76\end{array}$


Table 4 (continued)

Salience Inventory Scores for Retirees

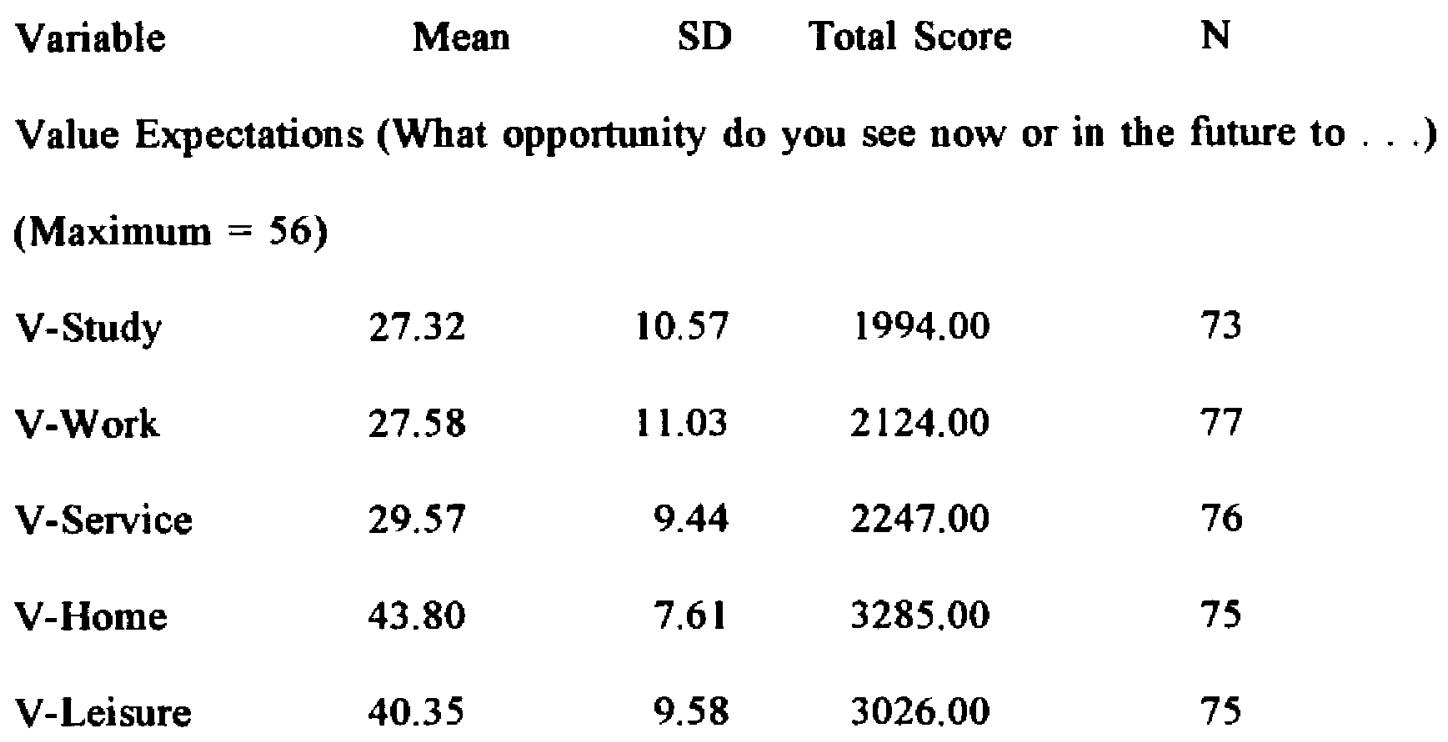




\section{Factor Analysis}

A factor analysis was used to identify factors that could serve as unifying constructs for the scale, role, and demographic variables. First, a correlation matrix for all purely demographic variables and the SI variables was computed (see Tables 5 and 6). Factor extraction and rotation (see Tables 7 and 8) were then used to ascertain how well the model fit the data and to make the factors more interpretable.

\section{Correlation Matrix}

The correlation matirx for all variables (Table 5) shows that 32 of the coefficients are greater than .27 in absolute value. (The highest absolute correlations are found between sets of the $P, C$, and $V$ scale variables and the life/career roles. Each variable except Q5 (Retirement Decision Type) has at least one high correlation with at least one other variable in the matrix.

Bartlett's test of sphericity was large (770.67230), and the significance level was small (.00000), indicating that the correlation matrix is not an identity matirx and that use of the factor model is appropriate.

\section{Factor Extraction}

Estimates of the initial factors were obtained from principal components analysis (see Table 7). Eigenvalues (total variance explained by each factor) for eight factors were greater than 1.0 , and $76.6 \%$ of the total variance was 
attributable to those eight factors. Therefore, it was determined that the eight factors might be adequate to represent the data. A factor structure matrix (Table 7) shows the factor loadings (standardized regression coefficients) for each factor. By squaring the coefficients for each variable, we obtained the amount of variance accounted for in each variable by each factor. The total variance accounted for by the retained factors is shown in the communalities listed in Table 7.

\section{Factor Rotation}

Varimax rotation was used to limit the number of variables with high loadings on a factor. This provides a simpler structure for interpretation. Table 8 shows the rotated factor matrix.

Review of the loadings suggested nomenclature for the factors. Factor 1 shows high loadings for P-Study, C-Study, V-Study, and Occupation. That factor was named "Self-Improvement." Factor 2 loaded high for P-Leisure, CLeisure, and V-Leisure, and V-Home and was named "R \& R." Factor 3, high for P-Service, C-Service, V-Service and Retirement Satisfaction (RS), was named "Giving Back." Factor 4, loading high for P-Work, C-Work, and VWork, was named "Vocational Purpose." Factor 5, high for P-Home, C-Home, V-Home, Occupation, and Q24 (Educational Attainment), was named "Home Base." Factor 6 was named "Occupation and Income," (high on Occupation 
and the two income variables, Q28/29). Factor 7, loading high on Q25 (Marital Status), Q26 (Household Size), and Q27 (Age) was named "Alone at Last," and Factor 8, loading high for Q5 (Retirement Decision Type) and RS2 (Retirement Satisfaction) was named "Voluntarily Retired." 
Table 5

Correlation Matrix for All Variables

P-Study P-Work P-Srve P-Hme P-L'sure C-Study C-Work

$\begin{array}{llllllll}\text { P-Study } & & & & & \\ \text { P-Work } & .22 & & & & & \\ \text { P-Service } & .13 & .07 & & & & \\ \text { P-Home } & .14 & .14 & .11 & & & & \\ \text { P-Leisure } & -.03 & .02 & -.11 & .40 & & & \\ \text { C-Study } & .87 & .23 & .09 & .07 & .02 & & \\ \text { C-Work } & .20 & .87 & -.02 & .13 & .10 & .28 & \\ \text { C-Service } & .16 & .13 & .81 & .13 & -.07 & .17 & .11 \\ \text { C-Home } & .07 & .01 & -.01 & .58 & .26 & .06 & .11 \\ \text { C-Leisure } & -.08 & .05 & -.17 & .08 & .70 & .03 & .10\end{array}$


Table 5 (continued)

\section{Correlation Matrix for All Variables}

P-Study P-Work P-Srve P-Hme P-L'sure C-Study C-Work

$\begin{array}{llllllll}\text { V-Study } & .84 & .21 & .15 & .09 & .02 & .84 & .22\end{array}$

$\begin{array}{llllllll}\text { V-Work } & .06 & .72 & -.02 & .04 & .11 & .09 & .77\end{array}$

$\begin{array}{lllllllll}V \text {-Service } & .15 & .14 & .76 & .01 & -.08 & .18 & .14\end{array}$

$\begin{array}{llllllll}\text { V-Home } & .06 & .02 & .05 & .52 & .38 & .03 & .01\end{array}$

$\begin{array}{llllllll}\text { V-Leisure } & .08 & .09 & -.12 & .16 & .66 & .14 & .09\end{array}$

$\begin{array}{lllllllll}\text { Occ } & -.27 & -.04 & -.12 & .07 & -.01 & -.34 & -.02\end{array}$

$\begin{array}{llllllll}\text { VolR } & .10 & .18 & .09 & -.11 & -.15 & .08 & .15\end{array}$

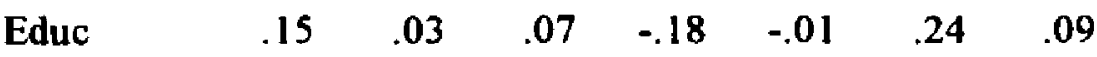

$\begin{array}{lllllllll}\text { MarSt } & -.06 & .15 & -.17 & -.11 & -.09 & -.11 & .19\end{array}$

$\begin{array}{lllllllll}\text { \#in hh } & -.08 & .14 & -.06 & -.13 & -.17 & -.14 & .14\end{array}$

$\begin{array}{lllllllll}\text { Age } & -.13 & -.19 & .07 & -.08 & -.06 & -.18 & -.17\end{array}$

$\begin{array}{llllllll}\text { Post R } & .10 & .17 & .12 & -.07 & .15 & .15 & .21\end{array}$

Inc

$\begin{array}{llllllll}\text { Pre R } & .24 & .08 & .15 & .06 & -.00 & .21 & .06\end{array}$

Inc

$\begin{array}{lllllllll}\text { RS } & & -.09 & -.01 & .14 & .14 & .22 & -.17 & -.12\end{array}$ 
Table 5 (continued)

Correlation Matrix for All Variables

$$
\text { C-Sve C-Hm C-Ls V-Sty V-Work V-Svc V-Home }
$$

C-Service

C-Home $\quad .10$

C-Leisure $\quad-.04 \quad .26$

$\begin{array}{llll}\text { V-Study } & .17 & .06 & -.01\end{array}$

$\begin{array}{lllll}\text { V-Work } & .03 & .01 & .08 & .16\end{array}$

$\begin{array}{lllllll}\text { V-Service } & .81 & .00 & -.04 & .21 & .17\end{array}$

$\begin{array}{llllllll}\text { V-Home } & -.03 & .62 & .34 & .11 & .11 & .10\end{array}$

$\begin{array}{llllllll}\text { V-Leisure } & -.07 & .19 & .80 & .19 & .16 & .06 & .58\end{array}$

$\begin{array}{lllllllll}\text { Occ } & & -.11 & .12 & .04 & -.32 & .12 & .00 & .13\end{array}$

$\begin{array}{llllllll}\text { VolR } & .12 & -.12 & -.12 & .15 & .17 & .16 & -.01\end{array}$

$\begin{array}{llllllll}\text { Educ } & .11 & -.11 & .08 & .13 & .04 & .15 & -.08\end{array}$

$\begin{array}{llllllll}\text { MarSt } & -.07 & -.04 & -.14 & -.12 & .19 & .01 & -.15\end{array}$

$\begin{array}{lllllllll}\text { \#in hh } & .04 & -.13 & -.08 & -.22 & .12 & .01 & -.29\end{array}$

$\begin{array}{lllllllll}\text { Age } & -.03 & .11 & -.02 & -.07 & -.21 & .02 & .07\end{array}$

$\begin{array}{llllllll}\text { Post R } & .15 & -.04 & .02 & .03 & .13 & .18 & -.12\end{array}$

Inc

$\begin{array}{llllllll}\text { Pre R } & .22 & -.00 & -.14 & .13 & -.03 & .23 & -.11\end{array}$

Inc

RS

$\begin{array}{lllllll}.10 & .13 & .17 & -.13 & -.06 & .17 & .27\end{array}$


Table 5 (continued)

Correlation Matrix for All Variables

$\begin{array}{llllllll}\text { V-Ls Occ VolR Educ MarSt \#in hh Age } & \begin{array}{l}\text { Post } \\ \text { Pre Inc }\end{array} \text { R Inc }\end{array}$

V-Ls

Occ $\quad-.04$

VolR $\quad .04 \quad .03$

Educ $\quad .09 \quad-.27 \quad .12$

MarSt -. $18 \quad .01 \quad-.06 \quad .12$

\#in hh-.21 $\quad .05 \quad-.05 \quad .13 \quad .63$

$\begin{array}{lllllll}\text { Age } & -.01 & .02 & -.06 & -.05 & -.13 & -.29\end{array}$

$\begin{array}{llllllll}\text { Post } & -.00 & -.12 & .12 & .36 & .29 & .12 & -.06\end{array}$

R Inc

$\begin{array}{lllllllll}\text { Pre } & -.11 & -.24 & .18 & .34 & .43 & .20 & -.06 & .62\end{array}$

R Inc

$\begin{array}{lllllllllll}\text { RS } & .20 & .07 & -.19 & -.13 & -.06 & -.00 & .14 & -.08 & -.02\end{array}$ 
The anti-image correlation matrix (Table 6) confirmed the appropriateness of the factor model, because the negatives of the partial correlation coefficients between pairs of the variables are small (with the linear effects of the other variables eliminated). The Kaiser-Meyer-Olkin (KMO) measure of sampling was in the "middling-mediocre" range $(0.70$ 's as "middling;" 0.60's as "mediocre") at (.62), considered good for a small sample of $\mathrm{N}=79$. The KMO level allows us to proceed with the factor analysis. Also, measures of sampling adequacy on the diagonals of the anti-image correlation matrix (Table 6) are large, a requirement for a good factor analysis. 
Table 6

Anti-Image Correlation Matrix

P-Study P-Work P-Srve P-Hme P-L'sure C-Study C-Work

$\begin{array}{lcccccccc}\text { P-Study } & .74 & & & & & \\ \text { P-Work } & -.14 & .61 & & & & & \\ \text { P-Service } & -.07 & -.23 & .62 & & & & \\ \text { P-Home } & -.07 & -.18 & .02 & .57 & & & \\ \text { P-Leisure } & -.00 & .34 & -.19 & -.50 & .61 & & \\ \text { C-Study } & -.59 & .08 & .18 & .06 & .04 & .70 & \\ \text { C-Work } & .13 & -.73 & .19 & -.02 & -.22 & -.26 & .62 \\ \text { C-Service } & .01 & -.06 & .45 & -.17 & .06 & -.02 & .02 \\ \text { C-Home } & .02 & .20 & .21 & -.25 & .10 & -.02 & -.23 \\ \text { C-Leisure } & .05 & .10 & .02 & .29 & -.38 & -.04 & .01\end{array}$


Table 6 (continued)

\section{Anti-Image Correlation Matrix}

P-Study P-Work P-Srve P-Hme P-L'sure C-Study C-Work

$\begin{array}{llllllll}\text { V-Study } & -.39 & .05 & .12 & .00 & -.02 & -.38 & .08\end{array}$

$\begin{array}{lllllllll}\text { V-Work } & & .02 & -.17 & .07 & .15 & -.11 & .25 & -.40\end{array}$

$\begin{array}{lllllllll}\text { V-Service } & .12 & .27 & -.36 & .11 & .17 & -.16 & -.20\end{array}$

$\begin{array}{llllllll}\text { V-Home } & -.05 & .01 & -.30 & -.29 & .18 & .01 & .10\end{array}$

$\begin{array}{llllllll}\text { V-Leisure } & .03 & -.14 & .29 & .09 & -.27 & -.01 & .12\end{array}$

$\begin{array}{lllllllll}\text { Occ } & & -.13 & .01 & .19 & -.06 & -.03 & .11 & .07\end{array}$

$\begin{array}{lllllllll}\text { VolR } & -.02 & -.05 & .06 & .13 & .06 & .17 & -.07\end{array}$

$\begin{array}{lllllllll}\text { Educ } & .04 & .12 & -.02 & .07 & .07 & -.14 & -.07\end{array}$

$\begin{array}{llllllll}\text { MarSt } & .03 & -.07 & .25 & .19 & -.14 & .15 & -.03\end{array}$

$\begin{array}{lllllllll}\text { \#in hh } & -.19 & .09 & -.12 & -.10 & .22 & .08 & -.09\end{array}$

$\begin{array}{llllllll}\text { Age } & -.08 & .08 & -.12 & .12 & .10 & .25 & -.16\end{array}$

$\begin{array}{lllllllll}\text { Post R } & .05 & .01 & -.14 & .20 & -.23 & -.12 & -.08\end{array}$

Inc

$\begin{array}{llllllll}\text { Pre R } & -.14 & -.10 & .10 & -.19 & -.02 & -.00 & .17\end{array}$

Inc

$\begin{array}{llllllll}\text { RS } & -.08 & -.25 & .08 & .10 & -.23 & .08 & .20\end{array}$ 
Table 6 (continued)

Anti-Image Correlation Matrix

C-Sve C-Hm C-Ls V-Sty V-Work V-Sve V-Home

C-Service $\quad .66$

C-Home $\quad-.32 \quad .47$

C-Leisure $\quad-.10 \quad-.40 \quad .60$

$\begin{array}{lllll}\text { V-Study } & .04 & -.09 & .12 & .77\end{array}$

$\begin{array}{llllll}\text { V-Work } & .08 & .06 & .08 & -.24 & .75\end{array}$

$\begin{array}{llllllll}\text { V-Service } & -.54 & .17 & .05 & -.01 & .16 & .64\end{array}$

$\begin{array}{lllllllll}\text { V-Home } & .36- & .62 & .27 & .11 & -.13 & -.13 & .52\end{array}$

$\begin{array}{lllllllll}\text { V-Leisure } & -.05 & .42 & -.63 & -.17 & -.00 & -.18 & -.63\end{array}$

$\begin{array}{lllllllll}\text { Occ } & & .09 & .08 & .02 & .16 & -.13 & -.28 & -.03\end{array}$

$\begin{array}{llllllll}\text { VolR } & -.08 & .04 & .14 & -.14 & .03 & .01 & -.05\end{array}$

$\begin{array}{lllllllll}\text { Educ } & .00 & .07 & -.06 & .07 & -.05 & -.01 & -.06\end{array}$

$\begin{array}{lllllllll}\text { MarSt } & .03 & -.01 & .09 & -.15 & -.01 & -.17 & -.17\end{array}$

$\begin{array}{lllllllll}\text { \#in hh } & & -.02 & -.04 & -.10 & .19 & -.01 & .08 & .23\end{array}$

$\begin{array}{lllllllll}\text { Age } & .12 & -.18 & .04 & -.09 & .19 & -.04 & .10\end{array}$

$\begin{array}{lllllllll}\text { Post R } & .04 & -.06 & .07 & .14 & -.01 & .04 & .04\end{array}$

Inc

$\begin{array}{lllllllll}\text { Pre R } & -.01 & -.05 & .04 & .08 & .05 & -.15 & .09\end{array}$

Inc

$\begin{array}{lllllllll}\text { RS } & & .03 & .00 & .02 & .06 & .05 & -.21 & .15\end{array}$ 
Table 6 (continued)

Anti-Image Correlation Matrix

$$
\begin{array}{lllllllll}
\text { V-Ls Occ } & \text { VolR } & \text { Educ } & \text { MarSt } & \# \text { in hh } & \text { Age } & \begin{array}{l}
\text { Post } \\
\text { R Inc }
\end{array} & \begin{array}{l}
\text { Pre } \\
\text { R Inc }
\end{array} & \text { RS }
\end{array}
$$

V-Ls $\quad .57$

Occ $\quad .06 \quad .62$

VolR $-.14 \quad-.12 \quad .54$

$\begin{array}{llll}\text { Educ } & -.04 \quad .16 & -.03 & .77\end{array}$

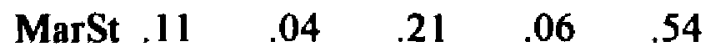

$\begin{array}{llllll}\text { \#in hh- } .10 & -.05 & -.02 & -.13 & -.59 & .54\end{array}$

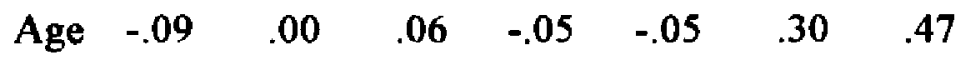

$\begin{array}{lllllllll}\text { Post } & -.02 & -.10 & .01 & -.15 & -.02 & .04 & -.01 & .65\end{array}$

R Inc

$\begin{array}{llllllllll}\text { Pre } & .02 & .21 & -.25 & -.15 & -.38 & .09 & -.02 & -.50 & .62\end{array}$

R Inc

$\begin{array}{llllllllllll}\text { RS } & .06 & .02 & .18 & .08 & .15 & -.17 & -.14 & .08 & -.07 & .54\end{array}$ 
Table 7

Initial Statistics, Factor Structure Matrix, and Final Statistics

Initial Statistics

Variable $\quad$ Communality * $\quad$ Factor Eigenvalue $\%$ of Var $\quad$ Cum $\%$

$\begin{array}{lllllll}\text { P-Study } & 1.00000 & * & 1 & 4.03344 & 16.8 & 16.8\end{array}$

$\begin{array}{lllllll}\text { P-Work } & 1.00000 & * & 2 & 3.56563 & 14.9 & 31.7\end{array}$

$\begin{array}{lllllll}\text { P-Service } & 1.00000 & * & 3 & 2.68469 & 11.2 & 42.8\end{array}$

$\begin{array}{lllllll}\text { P-Home } & 1.00000 & * & 4 & 2.34305 & 9.8 & 52.6\end{array}$

$\begin{array}{lllllll}\text { P-Leisure } & 1.00000 & * & 5 & 1.97143 & 8.2 & 60.8\end{array}$

$\begin{array}{lllllll}\text { C-Study } & 1.00000 & * & 6 & 1.55500 & 6.5 & 67.3\end{array}$

$\begin{array}{lllllll}\text { C-Work } & 1.00000 & * & 7 & 1.19940 & 5.0 & 72.3\end{array}$

$\begin{array}{lllllll}\text { C-Service } & 1.00000 & * & 8 & 1.02379 & 4.3 & 76.6\end{array}$

$\begin{array}{lllllll}\text { C-Home } & 1.00000 & * & 9 & .91082 & 3.8 & 80.4\end{array}$

$\begin{array}{lllllll}\text { C-Leisure } & 1.00000 & * & 10 & .80218 & 3.3 & 83.7\end{array}$

$\begin{array}{llllllll}\text { V-Study } & 1.00000 & * & 11 & .72482 & 3.0 & 86.7\end{array}$

$\begin{array}{lllllll}\text { V-Work } & 1.00000 & * & 12 & .64538 & 2.7 & 89.4\end{array}$

$\begin{array}{lllllll}\text { V-Service } & 1.00000 & * & 13 & .51202 & 2.1 & 91.5\end{array}$

$\begin{array}{lllllll}\text { V-Home } & 1.00000 & * & 14 & .43996 & 1.8 & 93.4\end{array}$

$\begin{array}{lllllll}\text { V-Leisure } & 1.00000 & * & 15 & .32246 & 1.3 & 94.7\end{array}$

$\begin{array}{lllllll}\text { Occ } & 1.00000 & * & 16 & .29172 & 1.2 & 95.9\end{array}$ 
Table 7 (continued)

Initial Statistics, Factor Structure Matrix, and Final Statistics

Initial Statistics

$\begin{array}{lllllll}\text { VolR } & 1.00000 & * & 17 & .21537 & .9 & 96.8 \\ \text { Educ } & 1.00000 & * & 18 & .18625 & .8 & 97.6 \\ \text { MarSt } & 1.00000 & * & 19 & .14606 & .6 & 98.2 \\ \text { \#in hh } & 1.00000 & * & 20 & .11673 & .5 & 98.7 \\ \text { Age } & 1.00000 & * & 21 & .10116 & .4 & 99.1 \\ \text { Post R } & 1.00000 & * & 22 & .08093 & .3 & 99.5 \\ \text { Inc } & & & & & & \\ \text { Pre R } & 1.00000 & * & 23 & .06574 & .3 & 99.7 \\ \text { Inc } & & & & & & \\ \text { RS } & 1.00000 & * & 24 & .06197 & .3 & 100.0\end{array}$


Table 7 (continued)

Initial Statistics, Factor Structure Matrix, and Final Statistics

Factor Structure Matrix

Factors

$\begin{array}{lllllllll}1 & 2 & 3 & 4 & 5 & 6 & 7 & 8\end{array}$

$\begin{array}{lllllllll}\text { P-Study } & .70 & -.04 & -.20 & -.51 & -.05 & .24 & -.12 & -.00\end{array}$

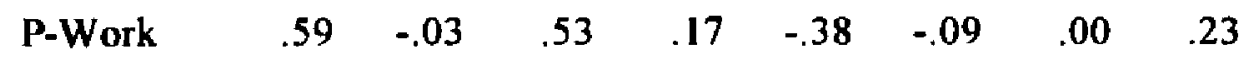

$\begin{array}{lllllllll}\text { P-Service } & .40 & .17 & -.62 & .51 & -.10 & -.11 & -.10 & -.00\end{array}$

$\begin{array}{lllllllll}\text { P-Home } & .23 & .52 & -.06 & .19 & -.11 & .58 & .07 & -.09\end{array}$

$\begin{array}{lllllllll}\text { P-Leisure } & .15 & .71 & .19 & .07 & .38 & -.11 & -.08 & -.03\end{array}$

$\begin{array}{lllllllll}\text { C-Study } & .74 & -.02 & -.16 & -.54 & -.00 & .10 & -.13 & -.01\end{array}$

$\begin{array}{llllllllll}\text { C-Work } & & .61 & -.01 & .59 & .14 & -.34 & -.07 & .05 & .21\end{array}$

$\begin{array}{lllllllll}\text { C-Service } & .50 & -.17 & -.51 & .54 & -.04 & -.09 & -.15 & -.09\end{array}$

$\begin{array}{lllllllll}\text { C-Home } & .15 & .57 & -.05 & .18 & -.03 & .55 & .20 & .01\end{array}$

$\begin{array}{lllllllll}\text { C-Leisure } & .12 & .69 & .21 & .03 & .36 & -.37 & -.18 & -.05\end{array}$

$\begin{array}{lllllllll}\text { V-Study } & .71 & .04 & .22 & -.52 & -.12 & .06 & -.08 & .01\end{array}$

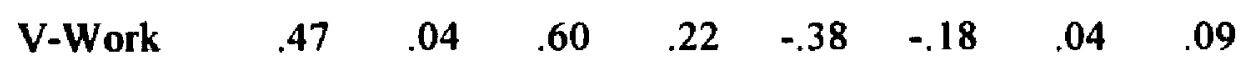

$\begin{array}{lllllllll}\text { V-Service } & .53 & -.14 & -.44 & .56 & -.04 & -.19 & -.09 & -.08\end{array}$

$\begin{array}{lllllllll}\text { V-Home } & .17 & .76 & -.08 & .16 & -.02 & .22 & .19 & -.11\end{array}$

$\begin{array}{lllllllll}\text { V-Leisure } & .26 & .74 & .13 & -.04 & .28 & -.37 & -.05 & -.13\end{array}$ 
Table 7 (continued)

Initial Statistics, Factor Structure Matrix, and Final Statistics

Factor Structure Matrix

\section{Factors}

$\begin{array}{llllllll}1 & 2 & 3 & 4 & 5 & 6 & 7 & 8\end{array}$

$\begin{array}{llllllllll}\text { Occ } & & -.32 & .14 & .17 & .34 & -.32 & .10 & .18 & -.31\end{array}$

$\begin{array}{llllllllll}\text { VolR } & .33 & -.19 & .02 & .00 & -.13 & -.28 & .56 & -.44\end{array}$

$\begin{array}{lllllllll}\text { Educ } & .33 & -.23 & .04 & -.07 & .50 & -.22 & .14 & -.01\end{array}$

$\begin{array}{lllllllll}\text { MarSt } & .06 & -.39 & .49 & .24 & .34 & .36 & -.10 & .04\end{array}$

$\begin{array}{llllllllll}\text { \#in hh } & -.01 & -.43 & .44 & .28 & .22 & .22 & -.42 & -.17\end{array}$

$\begin{array}{llllllllll}\text { Age } & -.22 & .11 & -.32 & .06 & .02 & -.09 & .41 & .65\end{array}$

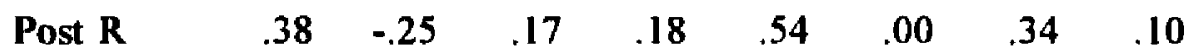

Inc

$\begin{array}{lllllllll}\text { Pre R } & .41 & -.35 & .01 & .14 & .57 & .29 & .27 & .02\end{array}$

Inc

$\begin{array}{llllllllll}\text { RS } & -.06 & .34 & -.16 & .38 & .10 & .03 & -.30 & .32\end{array}$ 
Table 7 (continued)

Initial Statistics, Factor Structure Matrix, and Final Statistics

Final Statistics

\begin{tabular}{llllllll} 
Variable & \multicolumn{1}{l}{ Communality } & $*$ & \multicolumn{2}{l}{ Factor Eigenvalue } & $\%$ of & Var & Cum\% \\
P-Study & .86545 & $*$ & 1 & 4.03344 & 16.8 & 16.8 \\
P-Work & .86910 & $*$ & 2 & 3.56563 & 14.9 & 31.7 \\
P-Service & .86413 & $*$ & 3 & 2.68469 & 11.2 & 42.8 \\
P-Home & .72946 & $*$ & 4 & 2.34305 & 9.8 & 52.6 \\
P-Leisure & .73709 & $*$ & 5 & 1.97143 & 8.2 & 60.8 \\
C-Study & .89845 & $*$ & 6 & 1.55500 & 6.5 & 67.3 \\
C-Work & .90920 & $*$ & 7 & 1.19940 & 5.0 & 72.3 \\
C-Service & .86900 & $*$ & 8 & 1.02379 & 4.3 & 76.6 \\
C-Home & .72359 & & & & & &
\end{tabular}


Table 7 (continued)

Initial Statistics, Factor Structure Matrix, and Final Statistics

Final Statistics

\begin{tabular}{|c|c|c|c|c|}
\hline Variable & Communality * & Factor Eigenvalue & $\%$ of Var & Cum\% \\
\hline V-Study & .85181 & & $*$ & \\
\hline V-Work & .82393 & & & \\
\hline V-Service & .86027 & & & \\
\hline V-Home & .73451 & & & \\
\hline V-Leisure & .86919 & & & \\
\hline Occ & .50408 & & & \\
\hline VolR & .71076 & & & \\
\hline Educ & .49252 & & & \\
\hline MarSt & .71644 & & & \\
\hline \#in hh & .75053 & & & \\
\hline Age & .77117 & & & \\
\hline $\begin{array}{l}\text { Post R } \\
\text { Inc }\end{array}$ & .69137 & & & \\
\hline $\begin{array}{l}\text { Pre R } \\
\text { Inc }\end{array}$ & .79949 & & & \\
\hline RS & .49275 & & & \\
\hline
\end{tabular}


Table 8

Rotated Factor Matrix

\section{Factors}

$\begin{array}{llllllll}\text { I } & 2 & 3 & 4 & 5 & 6 & 7 & 8 \\ \text { Self- } & \text { R\&R } & \text { Giving } & \text { Voc. } & \text { Home } & \text { Occ \& } & \text { Alone } & \text { Volunty } \\ \text { lmprove- } & \text { Back } & \text { Purpose } & \text { Base } & \text { Inc. } & \text { at Last } & \text { Retired } \\ \text { ment } & & & & & & & \end{array}$

$\begin{array}{lllllllll}\text { P-Study } & .91 & .07 & .07 & .08 & .13 & .07 & .06 & .04\end{array}$

$\begin{array}{lllllllll}\text { P-Work } & .14 & -.12 & .91 & -.03 & .03 & .05 & .06 & .01\end{array}$

$\begin{array}{lllllllll}\text { P-Service } & .08 & -.12 & .91 & -.03 & .03 & .02 & -.10 & -.02\end{array}$

$\begin{array}{lllllllll}\text { P-Home } & .09 & .08 & .07 & .05 & .83 & -.05 & .06 & -.08\end{array}$

$\begin{array}{lllllllll}\text { P-Leisure } & -.01 & .79 & -.08 & .04 & .28 & .09 & .01 & -.14\end{array}$

$\begin{array}{llllllllll}\text { C-Study } & & .93 & .05 & .07 & .12 & .03 & .09 & .04 & .08\end{array}$

$\begin{array}{lllllllll}\text { C-Work } & .15 & .04 & .01 & .93 & .05 & .10 & .06 & .04\end{array}$

$\begin{array}{lllllllll}\text { C-Service } & .11 & -.05 & .92 & .04 & .05 & .10 & .05 & .01\end{array}$

$\begin{array}{lllllllll}\text { C-Home } & .02 & .12 & -.01 & .02 & .83 & .02 & -.09 & -.09\end{array}$

$\begin{array}{lllllllll}\text { C-Leisure } & -.03 & .91 & -.07 & .05 & .04 & .01 & .01 & -.11\end{array}$

$\begin{array}{llllllllll}\text { V-Study } & & .89 & .04 & .11 & .13 & .07 & -.02 & -.06 & .12\end{array}$

$\begin{array}{lllllllll}\text { V-Work } & -.01 & .11 & .03 & .89 & .02 & -.01 & .10 & .12\end{array}$

$\begin{array}{lllllllll}\text { V-Service } & .06 & .02 & .91 & .12 & .01 & .12 & .01 & .05\end{array}$

$\begin{array}{lllllllll}\text { V-Home } & .01 & .43 & .06 & .01 & .71 & -.11 & -.15 & .05\end{array}$

$\begin{array}{lllllllll}\text { V-Leisure } & .10 & .91 & -.02 & .08 & .14 & .04 & -.06 & .06\end{array}$ 
Table 8

Rotated Factor Matrix

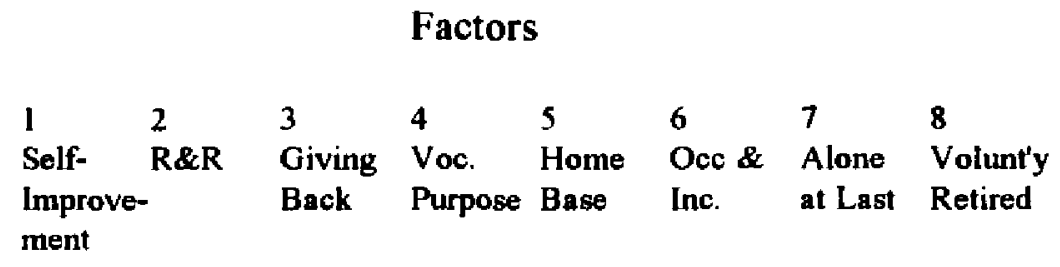

$\begin{array}{lcccccccc}\text { Occ } & -.50 & -.08 & -.03 & .08 & .29 & -.27 & .13 & .26 \\ \text { VolR } & .00 & -.03 & .15 & .14 & -.05 & .14 & -.06 & .80 \\ \text { Educ } & .19 & .19 & .08 & -.02 & -.28 & .56 & .00 & .14 \\ \text { MarSt } & -.17 & -.22 & -.15 & .20 & .01 & .55 & .47 & -.22 \\ \text { \#in hh } & -.20 & -.18 & -.01 & .14 & -.15 & .28 & .71 & -.24 \\ \text { Age } & -.16 & -.11 & -.00 & -.08 & .02 & .09 & -.82 & -.22\end{array}$


Table 8 (continued)

\section{Rotated Factor Matrix}

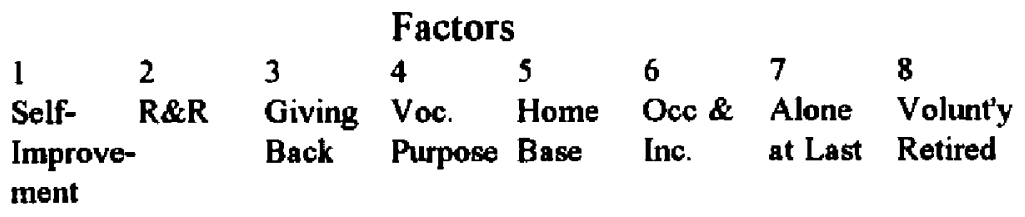

$\begin{array}{llllllllll}\text { Post } \mathrm{R} & & .02 & .07 & .09 & .14 & -.04 & .80 & .02 & .10\end{array}$

Inc

$\begin{array}{lllllllll}\text { Pre R } & .15 & -.13 & .14 & -.04 & .10 & .85 & .09 & .05\end{array}$

Inc

$\begin{array}{llllllllll}\text { RS } & -.18 & .23 & .26 & -.03 & .16 & -.07 & -.11 & -.54\end{array}$ 


\section{Regression Analysis}

A regression analysis (see Table 9) was conducted to determine whether the eight factors are important predictors of retirement satisfaction (RS) and to determine what weight each predictor variable contributed in predicting $\mathbf{R S}$. Independent variables were the eight factors. The dependent variable was retirement satisfaction (RS). Three procedures were used: forward, backward, and stepwise (see Table 9). Forward entry, with all variables in the equation, yielded an R Square of .60 (Adjusted R Square $=.49$ ). (Adjusted R Square in each case is lower than $\mathbf{R}$ Square, indicating attempts to correct $\mathbf{R}$ Square to achieve a better fit of the model in the population.) Backward elimination left Factor 7 out of the equation and an R Square of .59 (Adjusted R Square $=.50$ ). Stepwise entry reached tolerance levels after three factors were entered, leaving Factors 2,3 , and 8 in the equation but yielding a reduced $R$ Square of .46 (Adjusted R Square $=.41$ ).

The equation resulting from the backward procedure was chosen as the best fit for the model. This equation, as noted above, includes all the factors except Factor 7 ("Alone at Last"). Using the B's (partial regression coefficients) from this step as the coefficients for the factors yields the equation in Figure 1. 
$\mathrm{RS}=2.02-.43$ (Voluntarily Retired) +.09 (Home Base) +.16 (Giving Back) .16 (Vocational Purpose) $+.16(\mathrm{R} \& \mathrm{R})-.13$ (Occupation and Income) -.17 (Self-Improvement)

Figure 1. Regression equation: Predictors of retirement satisfaction. 
Table 9

Regression Analysis of the Predictors of Retirement Satisfaction

Forward Entry

\begin{tabular}{lc} 
Multiple R & .77 \\
R Square & .60 \\
Adjusted R Square & .49 \\
Standard Error & .53 \\
\multicolumn{3}{r}{ Analysis of Variance }
\end{tabular}

DF Sum of Squares

8

31

$F=5.76369$
13.09564

8.80436

Signif $F=.0002$
Mean Square

1.63696

.28401 
Table 9 (continued)

Regression Analysis

Backward Entry

Multiple R $\quad .76$

\begin{tabular}{l} 
R Square $\quad .59$ \\
\hline
\end{tabular}

Adjusted R Square $\quad .50$

Standard Error $\quad .53$

Analysis of Variance

$\begin{array}{lccr} & \text { DF } & \text { Sum of Squares } & \text { Mean Square } \\ \text { Regression } & 7 & 12.84123 & 1.83446 \\ \text { Residual } & 32 & 9.05877 & .28309 \\ \text { F }=6.48021 & \text { Signif F }=.0001 & \\ \quad \text { Factor } & \text { B } & -.43 \\ \text { Voluntarily Retired } & .09 \\ \text { Home Base } & .16 \\ \text { Giving Back } & -.16 \\ \text { Vocational Purpose } & .16 \\ \text { R \& R } & -.13 \\ \text { Occupation and Income } & -.17 \\ \text { Self-Improvement } & \end{array}$


Table 9 (continued)

\section{$\underline{\text { Regression Analysis }}$}

Stepwise Entry

Multiple R $\quad .67$

$\begin{array}{ll}\text { R Square } & \mathbf{4 6}\end{array}$

Adjusted R Square .41

Standard Error $\quad .58$

Analysis of Variance

$\begin{array}{lccr} & \text { DF } & \text { Sum of Squares } & \text { Mean Square } \\ \text { Regression } & 3 & 9.96640 & 3.32213 \\ \text { Residual } & 36 & 11.93360 & .33149 \\ \text { F }=10.02185 & & \text { Signif } F=.0001 & \end{array}$




\section{CHAPTER IV}

\section{DISCUSSION AND SUMMARY}

The sample for this study, a sample of convenience, reveals demography and satisfaction ratings that reflect an affluent, professional group of retirees, just as its responses to the SI reflect retirees who expect to bring satisfaction into their retirements. The results can be generalized to people who have recently retired (within the past two to four years), who are largely male, who were employed full-time in primarily professional and managerial positions, and who perceive they have had "careers." While this restriction of range is a limitation here, it affords us the opportunity to examine our working hypotheses and plan for further research. The data culled from the factor and regression analyses further bear this out.

As stated earlier, the purposes of this study were to examine the effects of perceived importance of the work role (commitment), the extent of participation in various life roles, and the value expectations attributed to life role activities on retirement satisfaction. The working hypotheses, in summary, stated that retired people with higher levels of participation, commitment, and perceived opportunities vis-a-vis "work-like activities" would have higher levels of retirement satisfaction than would retired people with lower levels of such 
participation, commitment, and perceived opportunities. The data offer initial support for these hypotheses, within the constraint of the nature of the sample.

The demographic data and retirement satisfaction ratings from the phone survey, revealing as they do a professional/managerial group of retirees who in no way were forced to retire and who do not suffer economically, show us people who engage in work-like activities ( $40.5 \%$ of the sample) in their retirements. They are an optimistic group, most highly satisfied with their interpersonal relationships and their perceived ability to age in place. Along with these aspects of retirement, they feel most satisfied with their levels of independence and autonomy, self-esteem, and how others perceive their retired status. The strong emphasis on home/family and leisure in the Salience Inventory (SI) data supports this as well. The respondents have the vocational history and personal and social support systems that can only benefit them in retirement.

But the data also show substantial participation and commitment to work and community service (a "work-like" activity), particularly when the SI scores for these two life/career roles are aggregated. When they are combined, work/service approaches the high score levels of the home/family and leisure roles. It is "home/family and leisure" that provide the base for satisfaction, but 
it is the purposefulness of work-like activities that rounds out the satisfying nature of the sample's retirements.

The results of the factor analysis amplify this, and the regression equation provides a good "fit" for the working hypotheses. The regression equation shows seven factors with varying influence on the level of retirement satisfaction perceived by the retirees in the sample. These factors are named:

Voluntarily Retired

Home Base

Giving Back

Vocational Purpose

$\mathbf{R} \& \mathbf{R}$

Occupation and Income

Self-Improvement

The seven factors reveal an underlying construct that includes elements of the desire for self-improvement, "r \& $r$," and a solid home base, along with the need for vocational purpose and the need to "give back" to the community (through service). The results support the theoretical constructs (see Chapter I) that underlie the working hypotheses and the concept of vocational script development. These theoretical constructs include the constructivist approach 
of proactive adaptation and work psychology's "continuing self," the recreation of self in the context of various life roles.

Working hypothesis \#1 is supported in general by the high correlations between Participation (P) and Commitment (C) and Value Expectations (V) scale scores. That is, those retirees who have participated most fully in worklike activities (in the work and community service roles) have the highest levels of expectation that they will continue to express their values within these roles in the future. Specific support for hypothesis \#1 is less clear from the results and points out another limitation of the study. Lack of resources precluded the conduct of preliminary qualitative research in the form of focus groups of retirees. Such qualitative investigation could have revealed the pattems of vocational script identification so that items eliciting such information could have been included in the phone questionnaire.

Working hypotheses $\# 2, \# 3$, and $\# 4$ are supported by the data. These hypotheses state that retired people who evidence higher levels of Participation (P), Commitment (C), and Value Expectations (V) for work-like activities (in the work and community service roles) will have greater retirement satisfaction (RS) than those who evidence lower levels of P, C, and V for work-like activities. As the regression equation shows, three key factors influencing RS are a need for "vocational purpose," desire for "self-improvement," and desire 
to "give back" to the community (through community service). These three factors each reflect high levels of Participation (previous involvement in worklike activities), Commitment (the degree of identification with work and community service roles), and Value Expectations (expected opportunity to engage in work-like activities). Hypothesis 4, specifically, gets significant support from the data. This hypothesis states that retired people who perceive they will have more opportunities to use their skills and knowledge in worklike activities will report higher levels of retirement satisfaction. That is, retirees with higher $\mathrm{P}$ scale scores will have higher $\mathrm{RS}$ scores. The factor analysis shows this to be the case. The three key factors influencing RS (vocational purpose, self-improvement desire, and giving back through community service) are essential elements of the concept of value expectations.

The results also can offer direction for design of pre-retirement planning and counseling programs. It is useful to group these programs into three specific areas of therapeutic assistance, all of which would use the tools of narrative and reminiscence. The first would entail helping individuals define the connections among their various life events and personality changes. As individuals engage in this effort they would learn how to remember, synthesize, summarize, and value their experience, all skills necessary for optimism and planfulness. Counselors operating in this phase enlist clients' ability to engage 
in a "life review." Clients are asked to define (in writing) a series of key events. These would include obvious events associated with relationships (birth, marriage, death) as well as failures and successes within life roles (as daughter or son, parent, student, spouse, partner, etc.) and within functional areas (home, school, play and leisure, and work). Clients are then asked to define levels of importance or value for each event with respect to the degrees of autonomy and agency they experienced at the time. This process engages clients in the activities of delineation, definition, values clarification, and synthesis, all activities essential for the development of self-awareness. At the end of this phase, clients have a retrospective map that shows the contours of these personalities, a kind of genealogy of personality.

The second area encourages people to define their work experiences as a career, leaming to identify themes and patterns of preferences and expertise, intrinsic and extrinsic rewards, and behavioral responses. It is at this point that a vocational script can take form and shape, providing the link between vocational and avocational activities in daily life from youth to old age. At this second level of intervention, counselors bring clients farther along to another dimension of "review." Using the skills of delineation, definition, clarification, and synthesis developed in the first phase, clients evaluate their work experience. For each work experience described earlier 
they are asked to define various vocational "features." These features would include patterns of relating to an occupational status hierarchy, valence of specific types of work rewardis, typical patterns of response to job seeking and job entry, the usual fabric of work relationships, the areas and types of skill and expertise that were developed, and the touch points for "burnout" and job exit. These features are then summarized by clients, with counselors' assistance, into career definitions. The career definition can be narrated, typed, and transcribed for use in the third area of counseling assistance.

The third counseling area focuses on the definition and enrichment of the future. Here the individual can sharpen skills in applying the vocational script to planning, becoming aware of the role of the script in perseverance, and developing autonomy within the roles and relationships of the later years of employment and the period of retirement.

In this last phase, counselors become good coaches, explaining, modeling, encouraging, and reinforcing development of the career definition into a vocational script. For clients this entails bringing the career of the past into the present and future by inserting a self-narrative into the career definition. In this process the career definition becomes a story of the self persevering, building autonomy and personal agency, feeling productive, and bringing these patterns into the future. Clients ramify their career definitions 
into truly vocational views of the self, descriptions of the specific individual patterns developed over the life span through vocational experiences, "call forth" self-definition. These vocational views, or scripts, are again narrated, taped, and transcribed, to be used in both explanatory (looking back at life roles and experiences) and predictive ways (looking forward to changes in work life and to aging and retirement.

Specific applications within these three areas work because they integrate memory and desire, past with present, present with future, and experience with goals.

Future research can develop further the working hypotheses of this study, replicating the study with a larger sample, investigating different socioeconomic and occupational status groups, and dimensionalizing the demographic information more comprehensively. Further work in the area of vocational script development and counseling for retirement satisfaction could focus on the role of voluntarism and community service in the lives of people who retire. It could illuminate the roles of increased community service activity and part-time employment among retirees in their perceived vocational agency. The relationship of the concepts of values expectations, commitment, and participation could be developed further within the context of counseling retirees in the development of vocational agency. And finally, a typology of 
retirement satisfaction could be hypothesized and investigated in order to increase our understanding of the specific elements of such satisfaction and how it might differ among various socioeconomic and cultural groups. 
APPENDIX A: HUMAN SUBJECTS FORMS

98 
MEHAVIORAL AND SOCIAL SCIENCES HUMAN SUDJECTS REVIEW COMMITTEF THE OHIO STATE UNIVEKSITY

$\times$ Original Revies - Continuing Review Amendment

Research involving Human Subjects

ACTION OF TIE REVIEW COMMITTEE

With regard to the employment of human subjects in the proposed research protocol

9430233

SATISFACTION WITH RETIREMENT: VOCATIONAL SCRIP'T DEVELOPMENT. Samuel 11. Osipow, Joan Simon, I'sychology

THE BEHAVIORAL AND SOCIAL SCIENCES REVIEW COMMITTEE HAS TAKEN THI: FOLLOWING ACTION:

APPROVED

X APPROVED WITH CONDITIONS*
DISAPPROVED

WAIVER OF WRITTEN CONSENT GRANTED

- Conditions stated by the Committee have been met by the Investigator and, therefore, the protocol is APPROVED.

\begin{abstract}
It is the respousibility of the principal investigator to retain a copy of each signed consent form for at least three (3) years beyond the termination of the subject's participation in the proposed activity. Should the principal investigator leave the University, signed consent torms are to be transferred to the Human Subjects Review Committee for the required retention period. This application has been approved for the period of one year. You are reminded that you must promptly report any problems to the Review Committec, and that no procedural changes may be made without prior review and approval. You are also reminded that the identity of the research participants must be kept confidential.
\end{abstract}

Date: August 12. 1994

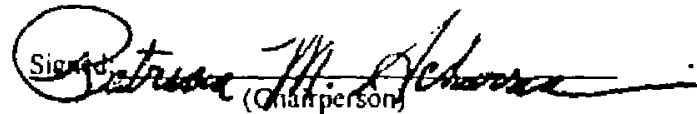

HS-025B (Rev. 2/94) 
BEHAVIORAL AND SOCIAL SCIENCES

HUMAN SUBJECTS REVIEW COMMITTEE (HSRC)

THE OHIO STATE UNIVERSITY

RESEARCH PROTOCOL:

Date Augusi 12,1994

9480233 SATISFACTION WITH RETIREMENT: VOCATIONAL SCAIPT DEVELOPMENT, SaTHUEI H. Osipow, Joan Simon, Psychology

presented for review by the Behavioral and Social Sciences Review Committee to ensure proper protection of the rights and welf are of the individuals involved with consideration of the methods used to obtain informed consent and the justification of risks in terms of potential benefits to be ganed, the Committee action was:

APPROVED

$\times$ APPROVED WITH CONDITIONS * NO REVIEW NECESSARY
DEFERRED*

DISAPPROVED

\section{-CONDITIONS/COMMENTS:}

Subjects were deemed NOT AT RISK and the protocol was unanimously APPROVED WITH THE FOLLOWING CONDITION:

1. Print letters to subjects on Osu letterhead and state the purpose of the study is co-investigator's dissertation research.

If you agree to the above conditions, PLEASE SIGN THIS FORM IN THE SPACE PROVIDED BELOW AND RETURN WITH ANY ADDITIONAL INFORMATION REQUESTED TO THE HUMAN SUBJECTS REVIEW DESK, 300 RESEARCH FOUNDATION, 1960 KENNY ROAD, CAMPUS, within one week. Upon such compliance, the approval form will be mailed to you. IIn case of a deferred protocol, please submit the requested information at your earliest convenience. The next meeting of the Committee will be two weoks from the meeting date indicated above.)

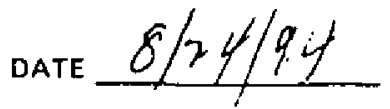

Signatures(s)

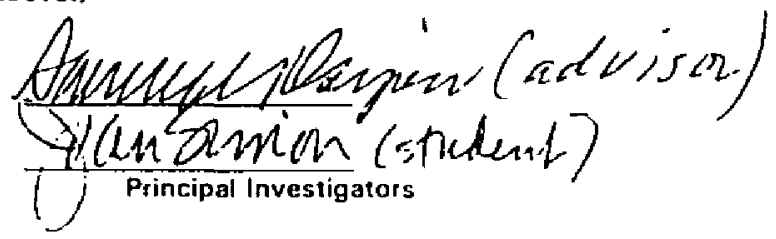


APPENDIX B: DEMOGRAPHIC/LIFESTYLE QUESTIONNAIRE 


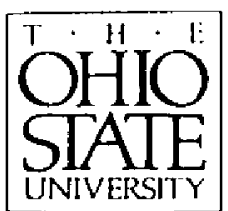

Departument of I'syclublugy

142 Tins moluend I tall

|RBS5 Notil Ave'tulu Mall|

Columbes bit $4.3214-1223$

(datc)

Dear Mail Survey Respondent

J want to thank you for agreeing to participate in lhis imponant survey. The purpose of this survey is to provide the information required for my dissenation research. Your responses to the cnclosed questionnaire, along with the responses of many other Upper Arlington retirees, will also assist the City of Upper Arlington in identifying various aspects of life in retirement and in planning effectively for the needs of older adults

As you will see, the enclosed survey questionnaire asks you to indicate your answers on a separate answer sheet. All directions are included for eaclı section of the questionnaire. It slould take you approximately 25 minutes to complete the questionnaire. I would suggest reading all the directions for all sections before you begin answering the questions. This will help familiarize you with how the questionnaire will proceed. Please be assured that strict confidentiality of your responses will be maintained.

When you have completed the questionnaire, it is extremely important that you return the answer sheet in the stamped envelope provided. Using this coded envelope mearns that we can match your answer sleet responses to your answers to the phone survey and still maintain confidentiality.

If there are parts of the questionnaire for which you need clarification, please call me at 488-2466. If I am not there, I will return your call.

After the mail survey is completed and all participants have sent in their answer sheets, the data will be analyzed. A report summary of the survey will be announced several months later and will be available through the City of Upper Arlington. I will remain available for consultation on results of the study for a period of time after the report summary is available.

Thank you once again for participating in this survey.

Very truly yours,

Joan Simon, Ph.D.

Samuel H Osipow, Ph.D. (Adviser) 
RETIREMENT SATISFACTION AND

DEMOGRAPHIC/LIFESTYLE QUESTIONNAIRE

I SCREEN/TALLY SECTION

RESPONDENT \#

TIME START:

TIME STOP $::_{-}$

INTERVIEWER ID.

\section{DO NOT READ RESPONSES UNLESS INSTRUCTED TO DO SO}

Hello, my name is I'm with CJI Research calling in connection with the Upper Arlington Senior Needs Study. May I please speak with any household member who is retired. Would there be such a person in your home? (GET NAME AND CALL BACK TIMES IF NECESSARY. ASK FOR REFERRAL TO OTHER RETIRED PERSON IF NECESSARY.)

(QUALIFY THE RESPONDENT): Hello Ms./Mr. . Let me explain the purpose of my call. Our firm is assisting Upper Arlington in their assessment of the needs of older people in the community by conducting this survey. This survey is the one that was just announced in the neighborhood paper and is sponsored in part by the Upper Arlington Commission on Aging and the Upper Arlington Senior Association. The results of this survey will help the City of Upper Arlington identify aspects of retirement that are critical in meeting the needs of older citizens. I have one initial survey question. Would you please tell me if you have been retired from active employment in a job outside the home for at least two years?

(IF YES, PROCEED. IF NO, GET REFERRAL TO OTHER RETIRED PERSON IF POSSIBLE.)

Good. Now, we have a brief survey we'd like to conduct with you. It should only take about ten to fifteen minutes of your time and would really be of 
value to us. Would you mind participating? (GET CALL BACK TIME IF NECESSARY. NOTE SEX AND PROCEED TO Q2 after tallying sex.)

1. SEX (TALLY)

1 male

2 female

(BALANCE SEX AS APPROPRIATE.)

2. Here's our first question. And be assured that all your responses are completely confidential. All identifying information from this phone survey will be stricken from all records when this survey is completed. Now, can you tell be for how many years you have been retired?

1 less than 2 years/greater than 4 years

\section{(TALLY, USE TERM SCRIPT, AND SAVE NAME/PHONE FOR REPLACEMENT GROUP)}

(TERM SCRIPT: "Thank you very much. We would like to have your permission to call you back later if we need to ask further questions in our survey. Would that be ok with you? IF YES, SAVE. Thank you for your time.")

2 between 2 and 4 years

(CONTINUE WITH

Q3)

9 ref
(TERM) 


\section{CAREER HISTORY/PERCEPTIONS}

3. And what was your primary occupation during the years you were employed?

(IF NECESSARY, ASK: "AND JUST EXACTLY WHAT DID YOU DO IN THAT OCCUPATION?" -- RECORD BELOW.)

(CODERS ONLY: CODE ABOVE OCCUPATION ACCORDING TO FOLLOWING LIST:)

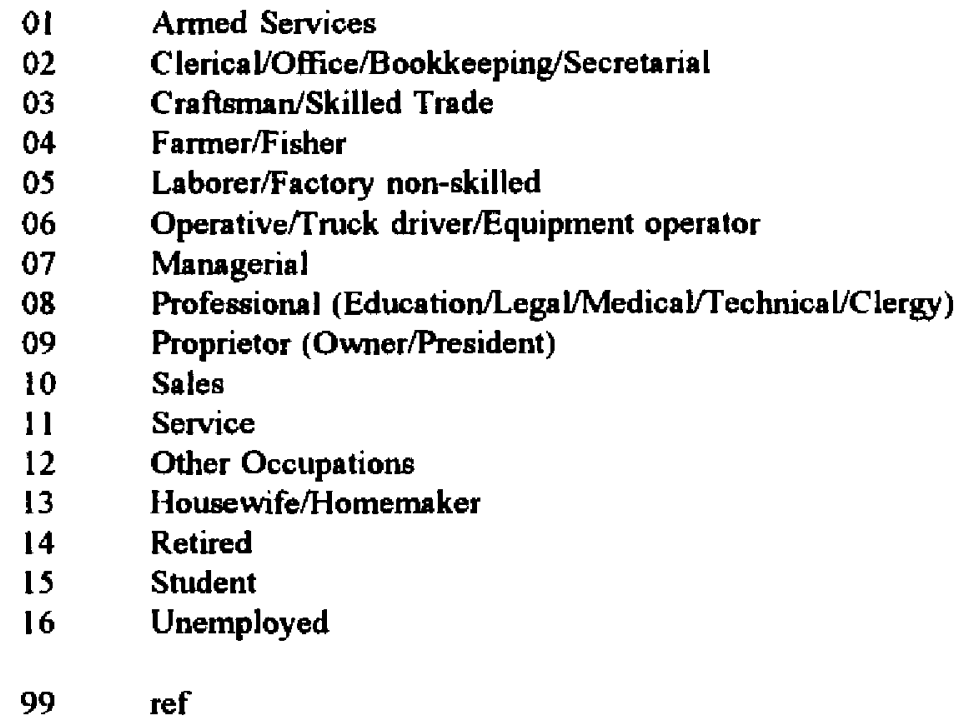

4. Were you usually employed full-time or part-time over the years you worked in this occupation?

1 Full-time (30 or more hours per week)

2 Part-time (less than 30 hours per week)

3 Varied (VOL)

9 ref 
4a. And are you now working part-time, volunteering, or would you say you are completely retired?

$\begin{array}{ll}1 & \text { part-time } \\ 2 & \text { volunteering } \\ 3 & \text { mixture (VOL) } \\ 9 & \text { ref }\end{array}$

4b. And is that work you're doing now very similar, somewhat similar, or not similar at all to the work you did prior to officially retiring?

$\begin{array}{ll}1 & \text { very similar } \\ 2 & \text { somewhat similar } \\ 3 & \text { not similar at all } \\ 8 & \text { unsure } \\ 9 & \text { ref }\end{array}$

5. And when you retired, was that a voluntary retirement on your part, or was it involuntary?

$\begin{array}{ll}1 & \text { voluntary } \\ 2 & \text { involuntary } \\ 9 & \text { ref }\end{array}$

6. Did you simply want to retire or was that some type of early retirement offer?

$\begin{array}{ll}1 & \text { wanted to retire } \\ 2 & \text { early retirement offer } \\ 3 & \text { both (VOL) } \\ 9 & \text { ref }\end{array}$

7a. Would you say you would have really liked to stay on in your job if you could have?

$\begin{array}{ll}1 & \text { yes } \\ 2 & \text { no } \\ 3 & \text { dk/unsure } \\ 9 & \text { ref }\end{array}$


7b. And would you say you had a "career," or would you say that over the time you worked you really just had a series of jobs and positions?

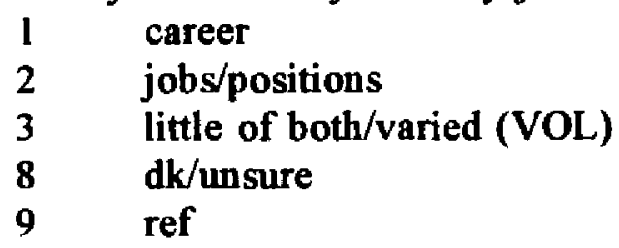

8. Many people who are retired tell us that they often find themselves doing things in retirement that are like the work they did when they were employed. Other people say the activities in their retirements are very different from when they were employed. What would you say? (REPEAT IF NECESSARY)

1 is like the work I did

2 activities are very different from work I did

3 a mixture

$4 \mathrm{dk} /$ unsure

9 ref

\section{RETIREMENT SATISFACTION}

9. And, overall, on a scale of one to ten, where one is very dissatisfied and ten is very satisfied, how satisfied would you say you are with your retirement in general?

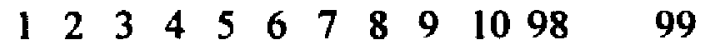

very dis. very sat. $d k$ ref

And now, on the same scale of one to ten, please tell me how satisfied you are with the following things: (DO NOT READ TITLES)

EXTENT OF POSITIVE SOCIAL CONTACT

10. the amount of contact you have with friends and other people you like to do things with

$\begin{array}{llllllllllll}1 & 2 & 3 & 4 & 5 & 6 & 7 & 8 & 9 & 10 & 98 & 99\end{array}$

very dis. very sat. $d k$ ref 


\section{QUALITY OF INTERPERSONAL RELATIONSHIPS}

11. the quality of your relationships with your friends

$\begin{array}{llllllllllll}1 & 2 & 3 & 4 & 5 & 6 & 7 & 8 & 9 & 10 & 98 & 99\end{array}$

very dis. very sat. $\mathbf{d k}$ ref

12. the quality of your relationships with people in your household

$\begin{array}{llllllllllll}1 & 2 & 3 & 4 & 5 & 6 & 7 & 8 & 9 & 10 & 98 & 99\end{array}$

very dis. very sat. $\mathrm{dk}$ ref

\section{QUALITY OF INVOLVEMENT IN COMMUNITY}

13. your involvement in community or neighborhood activities

$\begin{array}{llllllllllll}1 & 2 & 3 & 4 & 5 & 6 & 7 & 8 & 9 & 10 & 98 & 99\end{array}$

very dis. very sat. $\mathbf{d k}$ ref

\section{COMMUNITY COHESION}

14. how well your community or neighborhood pulls together on issues that affect the daily lives of residents

$\begin{array}{llllllllllll}1 & 2 & 3 & 4 & 5 & 6 & 7 & 8 & 9 & 10 & 98 & 99\end{array}$

very dis. very sat. $\mathbf{d k}$ ref

\section{ATTITUDES OF OTHERS TOWARD RETIREMENT STATUS}

15. the attitudes of other people toward you now that you are retired

$\begin{array}{llllllllllll}\text { I } & 2 & 3 & 4 & 5 & 6 & 7 & 8 & 9 & 10 & 98 & 99\end{array}$

very dis. very sat. dk ref

\section{HEALTH CONCERNS}

16. how concerned you are on a day-to-day basis with health insurance issues

$\begin{array}{llllllllllll}1 & 2 & 3 & 4 & 5 & 6 & 7 & 8 & 9 & 10 & 98 & 99\end{array}$

very dis. very sat. $\mathbf{d k}$ ref 
17. how concerned you are with your own health or that of someone else in your household

$\begin{array}{llllllllllll}1 & 2 & 3 & 4 & 5 & 6 & 7 & 8 & 9 & 10 & 98 & 99\end{array}$

very dis. very sat. $\mathbf{d k}$ ref

INDEPENDENCE AND AUTONOMY

18. how independent you feel

$\begin{array}{lllllllllllll}1 & 2 & 3 & 4 & 5 & 6 & 7 & 8 & 9 & 10 & 98 & 99\end{array}$

very dis. very sat. $\mathrm{dk}$ ref

19. how much control you feel you have now over the way in which you live

$\begin{array}{lllllllllllll}1 & 2 & 3 & 4 & 5 & 6 & 7 & 8 & 9 & 10 & 98 & 99\end{array}$

very dis. very sat. $\mathbf{d k}$ ref

PERCEIVED ABLITY TO AGE IN PLACE

20. the extent to which you will be able to stay in the place you live as you age

$\begin{array}{lllllllllllll}1 & 2 & 3 & 4 & 5 & 6 & 7 & 8 & 9 & 10 & 98 & & 99\end{array}$

very dis. very sat. $\mathrm{dk}$ ref

SELF-ESTEEM

21. how you feel about yourself and how well you're doing overall

$\begin{array}{llllllllllll}1 & 2 & 3 & 4 & 5 & 6 & 7 & 8 & 9 & 10 & 98 & 99\end{array}$

very dis. very sat. $\mathbf{d k}$ ref

\section{OPTIMISM}

22. how optimistic you feel about enjoying your retirement

$\begin{array}{llllllllllll}1 & 2 & 3 & 4 & 5 & 6 & 7 & 8 & 9 & 10 & 98 & 99\end{array}$

very dis. very sat. $\mathbf{d k}$ ref

PERCEIVED PERSONAL AGENCY 
23. the extent to which you think you are able to control how you live your life in retirement

$\begin{array}{llllllllllll}1 & 2 & 3 & 4 & 5 & 6 & 7 & 8 & 9 & 10 & 98 & 99\end{array}$

very dis. very sat. $\mathbf{d k}$ ref

\section{DEMOGRAPHICS}

And now I need to ask you just a few final questions that are for classification purposes only. In no way will your responses be identified with you personally. My first question is ...

24. What was the last grade in school you had the opportunity to complete? (READ RESPONSES)

1 Up through eighth grade?

2 Through high school graduation?

3 Some college or technical school?

4 College graduation?

5 Graduate or professional school?

9 (DO NOT READ) REFUSED

25. Are you single, married, widowed or divorced?

$$
\begin{array}{ll}
1 & \text { single } \\
2 & \text { married } \\
3 & \text { widowed } \\
4 & \text { divorced } \\
9 & \text { ref }
\end{array}
$$

26. How many people live in your household?

$$
99=\mathrm{ref}
$$


27. In what year were you born?

$$
\text { 99=-ref }
$$

28. And last, for classification purposes only, please stop me when I reach the group in which your household's total annual income falls...(READ

RESPONSES)

1 Under $\$ 10,000$ a year

2 Between $\$ 10,000$ and $\$ 30,000$

3 From $\$ 30,000$ to 50,000

4 From $\$ 50,000$ to 70,000

5 Above $\$ 70,000$

9 ref

29. And in what range was your household's total annual income before you retired?

(READ RESPONSES)

1 Under $\$ 10,000$ a year

2 Between $\$ 10,000$ and $\$ 30,000$

3 From $\$ 30,000$ to 50,000

4 From $\$ 50,000$ to 70,000

5 Above $\$ 70,000$

9 ref

(PROCEED WITH RECRUITMENT SCRIPT FOR MAIL SURVEY ON NEXT PAGE): 
"I want to thank you for participating in this survey. We also have a follow-up mail survey I would like to send to you. Your answers to the mail survey questionnaire will be very valuable to us in our study of retirement in Upper Arlington. May I send that mail questionnaire to you. Your identity will remain confidential. No return address on the mailed questionnaire will identify you. May I send that to you to fill out. (IF ASKED, IT WILL ONLY TAKE ABOUT HALF AN HOUR OF YOUR TIME) (IF ASKED, THE SURVEY WILL BE CONFIDENTIAL BECAUSE ONLY IDENTIFYING NUMBERS WILL BE USED. ALL ADDRESSES AND PHONE NUMBERS WLL BE DESTROYED.)

(CHECK DISPOSITION BELOW):

MAIL SURVEY AGREEMENT

MAIL

SURVEY SENT

(Y OR N)

DATE SENT

RESPONDENT NUMBER SENDER'S

INITIALS

FOLLOW-UP CALL TO MAIL SURVEY - DATE:

(INTERVIEWER MAKING CALL: 
APPENDIX C: CASRO CODE OF STANDARDS

FOR SURVEY RESEARCH 


\section{CASRO}

\section{Code ol Standards \\ for Survey Research}

\section{Inltodurtion}

This Code ol Standards for Survey Rescarch sels forth the agreed upon rules ol ethical conduct for survey research organizations. Acceptance of this Code is mandalory for all CASRO members.

The Code has been orpanized into sections describing the responsibilitics of a survey research organization to respondents, clients and outside contractors and in teporting siudy results.

This Code is nol Intended to be, ner should it be, an immulable document. Circumstances may arise that wo not covered by this Code or that may call for covered by this Code or that may call tor moditication of some sspect of this Cade. The Slandards Committee and the Board of
Oitectors of CASRO will evaluale these circumslances as they arise and. If appropriate, revise the Code. The Code, the refore, Is a living document that seeks to be responsive to the changing world of survey research.

\section{Responstbllilies to Respondents}

\section{A. Confidentlatly}

1. Survey research organizations we responsible for prolecting trom disclosure to third parties-including elients and members of the public-the idenlity of Individuat tespondents as well as respondentidentifiable informalion, uniess the respondent expressly permits such disclosure.

2. This principle of confidentizity is qualified by the following exceptions:

a. The identity of individual retpondents andiespondenl tdentifiable information may be disclosed to the client to permit the client: (1) to validate interviews and/or (2) to determine an additional lact of analytical imporlance to the study. In these cuses. te spondents must be given a sound resson lor the re-Irquing. $h$ all cases, a relusal by re spondent lo continue must be respected.

Belore disclosing iespondent-ldentifiable intormation to a clienl for purposes of interview validalion or re-inquiry, the survey research organization musi lake whalever steps are needed to ensure that the clien will conduct the validation or reconlact in tully protessional manner. This includes the - ovoidance of mulliple validation contacts or other conduet inat would harass or could other conduct ina would harass or emberiss uespondents. ha also includes any use of the inlonsalion lor oither than bona fide survey reseatch purposes or 10 respond to eustomey/respondent com. plainss. Assurance that the client will ie specl such limilations and maintain respondent condidenliality should be information is disclosed.

b. The idenlity of individual respondents andrespondentidentifiable informalion may be disclosed to othet survey research organ. izalions whenever euch otganizations are conducting diflerenl phases of a muly-stage study (e.0., a trend sludy). The inilial rese arch company should confirm ln witing that respondent confidentiality will to maintained in accordance with the code.

c. In the case of research In which representatives of the client or others ato present, such clienl representatives and others thould be askod not 10 discloso to anyone not present the identity of individual participants or other participantidantifying Inlormation excepl as needed to respond. wilh the participant's prior specilic approval, to any comptaint by one or moie or the participants concerning product or service supplied by the client.

3. The principle of respondent confidentiality includes the following specific applicalions or saleguaros:

a. Survey research organization slatf or personnel should not use or discuss respondent-identifiable data o information for other than legitimale inlernal esearch purposes.

b. The survey research organization has the responsibility for ensuring that subcontractors (inleviewers, Inteviewing services and validation, coding, and tabulation organizations) and consuttants te aware of and agree 10 mantaln respectespondent confidentiality whenever the identity of respondents or respondentidentiriable inlormation is disclosed to such entities.

c. Before permitting elients of others to have acoess to completed questionnaires in circumstances other than thase described bove. respondent names and other reve. respandent names and other be deleted.

d. hvislble identifiers on mail question. naires that connect respondent answers to parliculal respondents should not be used. Visible idenlification numbers may be used but thould be acoompanied by on explanation that such identifiers are to control purposes only and that iespondent confidentiality will nol be compromised.

e. Any survey research organization that receives trom a client of other entity intormation that it knows of teasonably believes ia be conlitientiat iespondentidentifiable information should decline to use such inlormation unless the information was disclosed in accordance with the principles and pracedures described in this Code

1. The use of survey lesults in a legal pro ceeding does not rclieve the survey rest arch organization s' its ellical abligation lis maimain in conludence all resrondent. identiluable information or lessen III importanoc of respondent monymity. conscournily survey iesearch firms contionted with subpoena of ather legal process requesting the disclosule of process requesting the disclostre of tespondontedenlifiable intormation should take all reasonable sleps to oppose such requests, including Informing the court of other decision-maker lnvolved of the tactors ustilying confidentiality and iespondent anonymity and interposing all epproprialc delenses to the request for disclosure.

B. Privacy and the Avoldance of Herastement

1. Survey iesearch organizations have a responsibility to strike a proper balance between the needs for research In contem. porary American lite and the privacy of individuals utio become the respondents in the research. To achieve this balance:

- Respondents will be protected from unnecessary and unwanted inlrusions and/or any form of personal harassment.

b. The voluntary character of the inlenvewerrespondent contact should be staled explicilly where the respondent might have reason to believe that cooperation is hot voluntary.

2. This principle of privacy includes the lollowing specilic applications:

- The research organization shall make every reasonable eflort to ensure that the respondent undersiands the purpose of the inlerviewer/respondent conlact.

(1) The Interviewer/research company representative must provide prompt and honest identification oi his/her iesearch firm afiliation.

(2) Respondent questions should be ensweced in a forthright and non-deceptive mannet.

b. Deceptive practices and misrep. resentation, such as using research as: guise for wales or solicitation purposes, we expressly prohibited.

c. Survey itsearch organizations must cespect the right of individusts lo refuse to be interviewed of lo terminate on inieview in progress. Techniques that inlringe on in progess. Techniques these righis should not be employed, but survey researth organizations may make reasonable efforts to obtain an inierview including: (1) explaining the purpose of the research project; (2) providing a or monelary Incentive adequale to elicit cooperalion: and (3) in the individual is unwilling or unable to participale ouring the iniljal contact.

d. Research organizalions are responsitle for arranging interviewing limes that ale convenient tor respondents. 
- Longthy inierviaws to buiden Research organlrations are responsible lor weighing the resoarch need gainst the length of the inturview and rospondents must not be enticed into on interview by mistepresentation of the tength of the interview.

1. Research organizations are responsible lor developing lechniques to minimiro the discomfort or apprehension ol respondents subject inatior.

Q. Electronic equipment plaping. recording pholographing) and one way riowing rooms may be used only with the viewing rooms may be used on

\section{Responsibullies to Cllents}

A Melationships between a survey research organization and clionts for whiom the survers ate conductod thould bo of such natule that they foster confidence and mulual rospect. They musl be characterized by fianesty and contidentiality.

B. The following specilic approaches des cribe in more detail the responsibilities of rescarch organizalions in this relationship:

1. A survey esearch organiration mus assisl its clients in the design of elfective and etticient sludies that are to be carried out by the research company. The survey research ofganization questions whe ther sludy design will provide the inlormation necessary lo serve the clienl's purposet, $n$ must make its teservations known.

2. A researeh organization must conduct the study in the manner agreed upon. However it it becomes eppuent in the course of the study that changes in the plans organization must make its views known to the client promplly.

3. Arese uch organization has an oblipation 10 Dlow his clients to verify that work performed meets ath contracted speci. richtions and to oxemine of operations of to the proper execution of the project in the manner tet lorth. Whils atlowing clients to examine questionnaires or other records. the survey research organization mus continue to protect the confidentiality and privacy of survey respondents.

4. When more than one client contributes to the cost of e project specially commissioned with the research organization, ach client with the research organization, wach client other participants fout not necessatily their olhel partici

5. Research organizations will hold confidenlial all information thal they obtain aboul a clienl's general business operations. and aboul matless connected with research projects that they conduct lor e clienl.

G For research findings oblained by the agency that are the property of the client. the cosearch oroanization may make no public relcase of ievelation of findings wilhout oxplesscd. prior approval trom the client

C. Bribery in any form and in any moun is unscoeplabie and is a violation of ese ech orgamizalion's lund amental, etthical alion and $/ 0$ is principals othicers and emplayees 5 thould never give gits to clionts in the form of cash. To the extent permitted by applicable laws and rogulations, a resesc organization may provide nominal gitts 10 clients and may ontertain clienls, as long as the cost of such ontertainment is modest in mount and incidental in naturo.

\section{$\frac{\text { III. Responslbilltles In Reporting }}{\text { to Clients and the Pubile }}$}

A When reports are being prepared fo clienl confidential or public release pulposes, it is the obligation ol the rese arch organization to ensure that the findings they release are an accurate portrayal of the survey data, and carelul checks on the accuracy of all figures are mandalory.

B. A research organizalion's repon to a client of the public should contain, of the research organizalion should be roady to supply on short notice, the following informalion bout the survey:

The name of the organization for which the study was conducted and the name of the organization conducting th.

2. The purpose of the study, including the specific objectives.

3. The dates on or between which the tieldwork was done.

4. A definition of the universe that the survey is intended to represent and deseription of the population Irame (s) tha was actually sampled.

5. A descaiption of the sample design, including the method of telecting sumple - lements, method of interview, cluster size. number of callbucks, respondent eligibility number of callbscks, respondent eligibility or screening

6. A description of iesults of sample implementation including (a) lotal number of sample elements contacted, (b) the number not reached, (c) the number of relusals, (d) the number of terminations, (e) the number of noneligibles, (i) the number of compleled intervitwo

7. The basis for any specilic completion rale" percenlages should be tully documented and described.

8. The exact wording of the questions used including interviewer ditections and visual exhibits

9 A description of any weighting o estimaling procedures used
10. A descriplion of any special scoring. dala djustment of indexing procedures used. Mirere the research organization usos proprietary techniques, these sliould be described in penetal and the lescaich organizalion should be prepared to provide technical inloumation on demand liom qualilied and teclinically competent persons who have ngreed to honor the conlidenliality of such inlormation.

11. Estimales of the sampling efror and of dala shown when appropriale, but when shown they should Include reference to other possible sources of etrot so that inislesding impression

12. Siatistical tables clearly labelied and idenlitied as to questionaire soutce. including the number of raw cases forming the base for each cross-labulation.

13. Copies of interviewer instruttions. validation iosults, codo books, and other infortanl wolking papers

C. As a minimum, any general public rele ase of survey findings should include the lollowing inlo'mation:

1. The sponsorship of the sludy

2. A descriplion of the putposes.

3. The sample description and size.

4. The dales of fieldwork.

5. The names of the researeh agency condueting the study.

6. The exact wording of the questions.

7. Any other intormation that a layperson would need to make reasonable issessment of the reported findings.

D. A survoy research organization will seek areernents from clients so that citations of survey findings will be presented to the research organization for review and clearance to to cocuracy and proper interpratation prior to public release interpretalion pror to public release. A if the survey findings publicly disclosed are incorrect, distorted, or incomplete. In the research organization's opinion, the research organization reserves the right to make its own release of any or all survey lindings necessary to make clarification.

\section{Aesponsibllity to Outside Coniractors} and Intervlewers

Research organizalions will not ask any outside contractor or inle rviewer to engage in any activity which is nol acceplable as defined in othes sections of this Code of Standards lor Survey Meseasch.

$$
\text { - } \cdot
$$

Council of American-Survey itescarct Organizations. 3 Uppei Devon. Belle Jerre. Port delterson, WY 11777 (516)9?B 6954 
APPENDLX D: PERMISSIONS

116 
254: Hexky Bark Rund

Conlumbus $\mathrm{OH} 43200$

(c) $6.14-237-4016$

li1x 614-237-6047
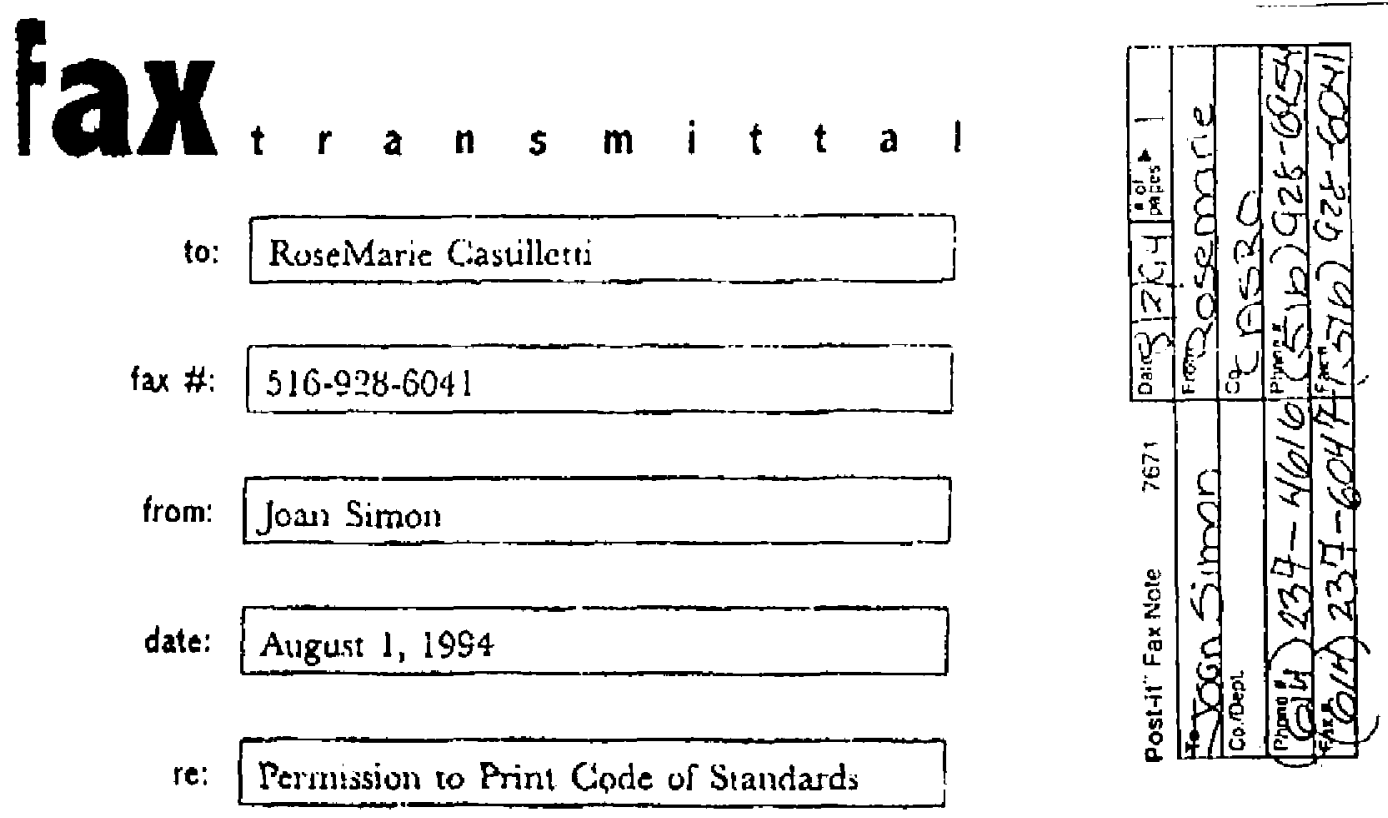

pages: 1 , including this cover sheee

NOTES: As you stiggesicd, I arm laxing resy request for permission to use the short form of the Code of Sianclards for Survcy Research in the appendix to my dissertation, I an a graduate student in the Department of Fsycholog) at The Ohio State Universily (Adviser: Dr. Samuel Osipow, 614-292-1748;. The Codo will evidence nuy artention to the standards as I fieje! a icleplione and inatil sulvey io collect data for sie disscration. 'The surveys wall be coldacacd wii): a sample of rerired people in a suburb of Colatublis, Ohio. The

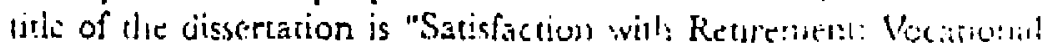
Scrijut Development."

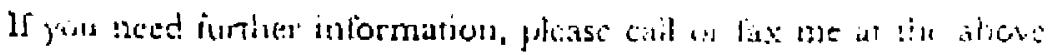

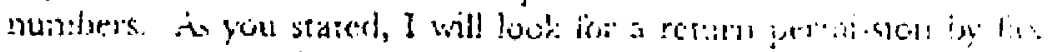

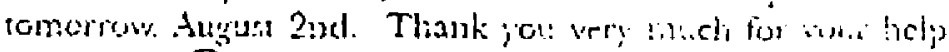

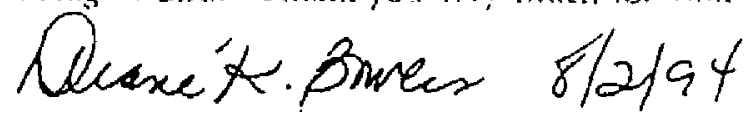



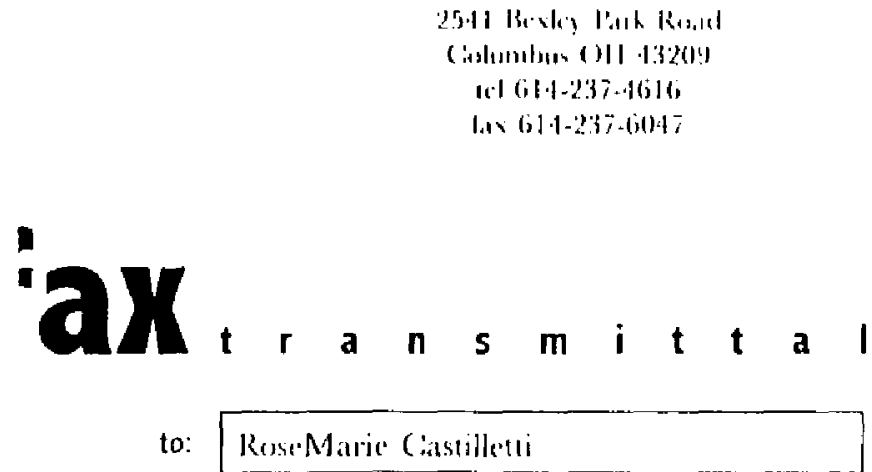

$\operatorname{tax} f t: 510.9283-6011$

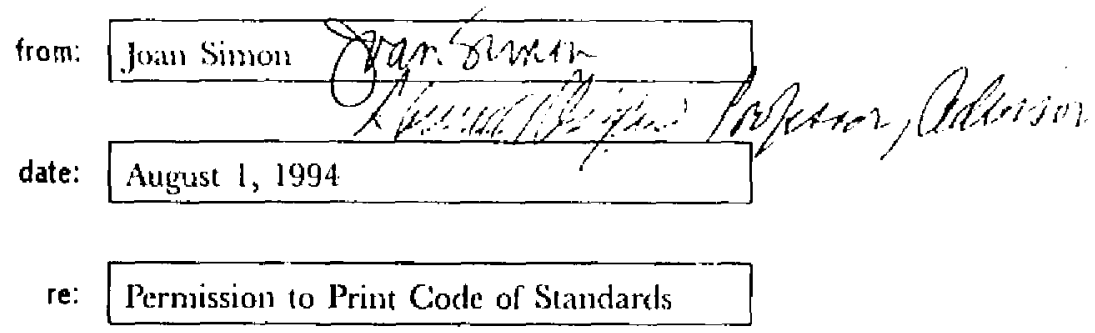

pages: 1 , including this cover sheet

NOTES: As you suggested, I an faxing my request for permission to use the short form of the Code of Standards for Survey Research in the appendix to my dissertation. I am a graduate student in the Deparment of Psychology at The Ohio State University Artvisen: Dr. Samuel Osipow, 614-292-1748). The Code will evidence ny attention to the standards as 1 ficld a telephone and mail sursey to collect data for the dissertation. The surveys will be conducted with a sample of retired people in a suburb of Columbus, Olio. 'The' litle of the dissertation is "Satisfaction with Relirement: Vocational Sicript Development."

If you theed furdser information. please call or fax me at ilu above: mumbers. As you stated, l will look for a returs permission ix fax tomorrow; August 2nd. Thank you very much for your help. 


\section{LIST OF REFERENCES}

Altergott, K. (1988). Social action and interaction in later life: Aging in the United States. In K. Altergott (Ed.), Daily life in later life: Comparative perspectives, (pp. 117-146). Newbury Park, CA: Sage Publications.

Antonovsky, A., \& Sagy, S. (1990). Confronting developmental tasks in the

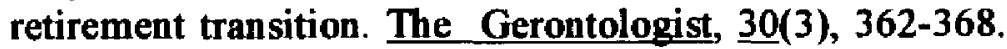

Atchley, R. C. (1991). Social forces and aging: An introduction to social gerontology (6th ed.), Belmont, CA: Wadsworth Publishing Company.

Bandura, A. (1991). Social cognitive theory of self-regulation. Organizational Behavior and Human Decision Processes, 50, 248-287.

Beehr, T. A. (1986). The process of retirement: A review and recommendations for future investigation. Personnel Psychology, 39(1), $31-55$.

Berger, P., \& Luckmann, T. (1979). The social construction of reality. Middlesex, England: Penguin Books, Ltd.

Bowlby, J. (1969). Attachment and loss: Vol. 1. Attachment. New York, NY: Basic Books.

Brubaker, T. H., \& C. B Henon. (1982). Responsibility for household tasks: Comparing dual-eamer and dual-retired marriages. In $\mathrm{M}$. Szinovacz (Ed.), Women's Retirement (pp. 205-220). Beverly Hills, CA: Sage.

Butler, R. N. (1963). The life review: An interpretation of reminiscence in the aged. Psychiatry, 26, 65- 76.

Campbell, R. E., \& Heffernan, J. M. (1983). Adult vocational b ehavior. In W. B. Walsh \& S. H. Osipow (Eds.), Handbook of vocational psychology (Vol. 1) (pp.223-260). Hillsdale, NJ: Erlbaum. 
Carlsen, M. B. (1988). Meaning-making: Therapeutic processes in adult development. New York: W. W.Norton \& Company.

Carlsen, M. B. (1991). Creative aging: A meaning-making perspective. New York: W. W. Norton \& Company.

Carlson, R. (1981). Studies in script theory: I. Adult analogs of a childhood nuclear scene. Joumal of Personality and Social Psychology, 40, 50 I510.

Cohler, B. J., \& Grunebaum, H. (1981). Mothers, grandmothers, and daughters: Personality and Child Care in three-generation families. New York: Wiley.

Datan, N., Rodeheaver, D., \& Hughes, F. (1987). Adult development and aging. Annual Review of Psychology, 38, 153-180.

Dobson, C., \& Morrow, P. C. (1984). Effects of career orientation on retirement attitudes and retirement planning. Journal of Vocational Behavior, 24, 73-83.

Ekerdt, D. J. (1986). The busy ethic: Moral continuity between work and retirement. The Gerontologist, 26, 239-244.

Erikson, E. H. (1963). Childhood and society. New York: Norton.

Erikson, E. H. (1968). Identity, youth, and crisis. New York: Norton.

Erikson, E. H., \& Erikson, J. M. (1986). Vital involvement in old age. New York: Norton.

Fisseni, H. (1985). Perceived unchangeability of life and some biographical correlates. In Munnichs, J. M., Mussen, P., Olbrich, E., \& Coleman, P. G. (Eds.), Life-span and change in a gerontological_perspective (pp. 103-132). Orlando: Academic Press.

Freeman, M. (1984). History, narrative, and life-span developmental knowledge. Human Development, 27, 1-19. 
Friedan, B. (1993). The fountain of age. New York: Simon \& Schuster.

Goffman, E. The presentation of self in everyday life. Garden City, NY: Doubleday Anchor Books.

Guidano. V. F. (1984). A constructivist outline of cognitive processes. In M.A. Reda \& M. J. Mahoney (Eds.), Cognitive psychotherapies: Recent developments in theory, research, and practice (pp. 31-45). Cambridge, MA: Ballinger.

Guidano, V. F. (1987). Complexity of the self: A developmental approach to psychopathology and therapy. New York: The Guilford Press.

Guidano, V. F. (1991). The self in process: Toward a post-rationalist cognitive therapy. New York: The Guilford Press.

Haight, B. K. (1982). Haight's life review and experiencing form. College of Nursing, Medical University of South Carolina, Charleston, S.C.

Haight, B. K. (1988). The therapeutic role of a structured life review process in homebound elderly subjects. Journal of Gerontology: Psychological Sciences, $\underline{43}(2), 40-44$.

Haight, B. K. (1989). Life review: A method for pastoral counseling. Joumal of Religion \& Aging, $5, \quad 17-29$.

Haight, B. K. (1992). Reminiscence and life review: Conducting the processes. Journal of Gerontological Nursing, $\underline{86}, 39-42$.

Havighurst, R. J., Munnichs, J. M., Neugarten, B., \& Thomae, H. (1969). Adjustment to retirement: a cross-national study. The Netherlands: Koninklijke Van Gorcum \& Comp. N. V.

Havighurst, R. J., \& Glasser, R. (1972) An exploratory study of reminiscence. Journal of Gerontology, 17, 245-253.

Herr, E. L., \& Cramer, S. H. (1988). Career guidance and counseling through the life span: Systematic approaches (3rd ed.). Harper Collins Publishers. 
Hitchcock, A. A. (1984). Current trends: Work, aging, and counseling. Journal of Counseling and Development, $\underline{63}$ (4), 258-259.

Howard, J. H., Rechnitzer, P. A., Cunningham, D. A., \& Donner, A. P. (1986). Change in type $A$ behavior a year after retirement. The Gerontologist, 26(6), 643-649.

Johnson, R. P., \& Riker, H. C. (1981). Retirement maturity: A valuable concept for preretirement counselors. The Personnel and Guidance Journal, 59(5), 291-295.

Kerckhoff, A. C. (1966). Norm-value clusters and the strain toward consistency among older married couples. In I. H. Simpson \& J. C. McKinney (Eds.), Social aspects of aging (pp. 138-159). Durham, NC: Duke University Press.

Labouvie-Vief, G. (1984). Logic and self regulation from youth to maturity. In M. L. Commons, F. A. Richards, \& C. Armon (Eds.), Beyond formal operations: Late adolescent and adult cognitive development. New York: Praeger.

Lemer, R. M., \& Busch-Rossnagel, N. (Eds.). (1981). Individuals as producers of their own development. New York: Academic.

Levinson, D. J. (1986). A conception of adult development. American Psychologist, 41 , (1), 3-13.

Lewis, C. (1971). Reminiscing and self-concept in old age, Journal of Gerontology, 26, 240-243.

Liotti, G. (1988). Theoretical underpinnings of structural cognitive therapy. In C. Perris \& M. Eisemann (Eds.), Cognitive psychotherapy: An update. Umea, Sweden: DOPUU Press.

Loesch, L. C. (1980). Life-flow leisure counseling for older persons. Journal of Employment Counseling, 17(1), 49-56.

Lofquist, L. H., \& Dawis, R V. (1969). Adjustment to work. Englewood Cliffs, NJ: Prentice-Hall. 
Mahoney, M. J., \& Lyddon, W. J. (1988). Recent developments in cognitive approaches to counseling and psychotherapy. The Counseling Psychologist, 16, (2), 190-234.

Mair, M. (1989). Kelly, Bannister, and a story-telling psychology. Intemational Journal of Personal Construct Psychology, 2, 1- 14 .

McAuliffe, G. J. (1993). Constructive development and career transition: Implications for counseling. Journal of Counseling \& Development, 72 , 23-28.

McMahon, A. W., \& Rhudick, P. J. (1964). Reminiscence: adaptational significance in the aged. Archives of General Psychiatry, 10, 292-298.

Musgrove, M. L. (1992, November). Psychodynamic career counseling. Lecture given to class in Counseling Psychology. The Ohio State University, Columbus, $\mathrm{OH}$.

Nevill, D. D., \& Super, D. E. (1986). The salience inventory: Theory,application, and research -- manual (Research Edition). Palo Alto: Consulting Psychologists Press.

Osipow, S. H. (1983). Theories of career development (3rd ed.). Englewood Cliffs, NJ: Prentice-Hall.

Payne, E. C., Robbins, S. B., \& Dougherty, L. (1991). Goal directedness and older-adult adjustment. Journal of Counseling Psychology, 38(3), 302-308.

Peskin, H., \& Livson, N. (1981). Uses of the past in adult psychological health. In Eichorn, D. H., Clausen, J. A., Haan, N., Honzik, M. P., \& Mussen, P. H. (Eds.), Present and past in middle life (pp. 153-181). New York: Academic Press.

Richardson, M. S. (1993). Work in people's lives: A location for counseling psychologists. Joumal of Counseling Psychology, 40 (4), 425-433. 
Sarbin, T. R. (1986). The narrative as a root metaphor for psychology. In T. R. Sarbin (Ed.), Narrative psychology: The storied nature of human conduct (pp. 3-21). New York: Praeger.

Savickas, M. L. (1989, March). Work and love: Life's two passions. Paper presented at the Annual Convention of the American Association for Counseling and Development, Boston, MA.

Savickas, M. L. (1990, January). Career interventions that create hope. Paper presented at the National Conference of the National Career Development Association, Scottsdale, AZ.

Savickas, M. L. (1992, March). Career counseling using the narrative paradigm. Paper presented at the Annual Convention of the American Association for Counseling and Development, Baltimore, MD.

Schafer, R. (1992). Retelling a life: Narration and dialogue in psychoanalysis. New York: Basic Books.

Schein, E. H. (1978). Career dynamics: Matching individual and organizational needs. Reading, MA.: Addison-Wesley Publishing Company.

Schlossberg, N. K. (1976). The case for counseling adults. The Counseling Psychologist, 6, (1), 33-36.

Schlossberg, N. K. (1981). A model for analyzing human adaptation to transition. The Counseling Psychologist, 9(2), 2-18.

Sherman, E. (1991). Reminiscence and the self in old age. New York: Springer Publishing Company.

Smyer, M. A. (1984). Life transitions and aging: Implications for counseling older adults. The Counseling Psychologist, 12(2), 17-28.

Super, D. E. (1976). Career education and the meaning of work. Monographs on career education. Washington, DC: The Office of Career Education, U.S. Office of Education. 
Super, D. E. (1982). The relative importance of work: Models and measures for meaningful data. The Counseling Psychologist, 10(4), 95-103.

Super, D. E. (1983). Assessment in career guidance: Toward truly developmental counseling. The Personnel and Guidance Journal, May 1983, 555-562.

Super, D. E. (1984). Career and life development. In D. Brown \& L. Brooks (Eds.), Career choice and development, applying contemporary approaches to practice. San Francisco: Jossey-Bass.

Super, D. E., \& Nevill, D. D. (1985). The salience inventory. Palo Alto: Consulting Psychologists Press.

Super, D. E., \& Nevill, D. D. (1986). The values scale. Palo Alto, CA: Consulting Psychologists Press.

Tarman, V. I. (1988). Autobiography: The negotiation of a lifetime. International Joumal of Aging and Human Development, 27 (3), 171191.

Tiedeman, D. V., \& O'Hara, R P. (1963). Career development: choice and adjustment. New York College Entrance Examination Board.

Tiedeman, D. V., \& Miller-Tiedeman, A. (1977). An "I" power primer: Part one: Structure and its involvements of intuition. Focus on Guidance, 9(7), 1-16.

Tobin, S. S. (1985). Psychological adaptation to stress by the elderly. In B. B. Davis \& W. G. Wood (Eds.), Homeostatic function and the aged, (pp. 181-195). New York: Raven.

Tomkins, S. S. (1979). Script theory: Differential magnification of affects. In H. E. Howe, Jr. \& R. A. Dienstbier (Eds.), Nebraska Symposium on Motivation (Vol, 26). Lincoln: University of Nebraska Press.

Tomkins, S. S. (1987). Script theory. In J. Aronoff, A. I. Rabin, \& R. A. Zucker (Eds.), The emergence of personality (pp. 147-216). New York: Springer Publishing Company. 
Varela, F. J. (1979). Principles of biological autonomy. New York: Elsevier North Holland.

Vinick, B. H., \& Ekerdt, D. J. (1989). Retirement and the family. Generations, 13(2), 53-56.

Westcott, N. A. (1983). Application of the structured life-review technique in counseling elders. The Personnel and Guidance Journal, 62(3), 180187.

Zeleny. M. (Ed.). (1981). Autopoiesis: A theory of living organization. New York: North Holland. 